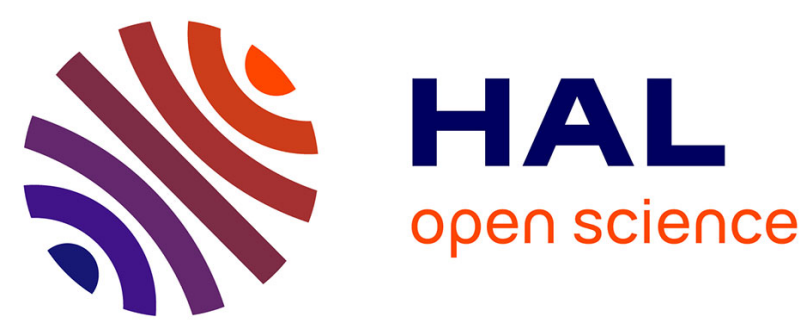

\title{
Application of the continuum shell finite element SHB8PS to sheet forming simulation using an extended large strain anisotropic elastic-plastic formulation
} Abdellah Salahouelhadj, Farid Abed-Meraim, Hocine Chalal, Tudor Balan

\section{To cite this version:}

Abdellah Salahouelhadj, Farid Abed-Meraim, Hocine Chalal, Tudor Balan. Application of the continuum shell finite element SHB8PS to sheet forming simulation using an extended large strain anisotropic elastic-plastic formulation. Archive of Applied Mechanics, 2012, 82 (9), pp.1269-1290. 10.1007/s00419-012-0620-x . hal-00800281

\section{HAL Id: hal-00800281 \\ https://hal.science/hal-00800281}

Submitted on 13 Mar 2013

HAL is a multi-disciplinary open access archive for the deposit and dissemination of scientific research documents, whether they are published or not. The documents may come from teaching and research institutions in France or abroad, or from public or private research centers.
L'archive ouverte pluridisciplinaire HAL, est destinée au dépôt et à la diffusion de documents scientifiques de niveau recherche, publiés ou non, émanant des établissements d'enseignement et de recherche français ou étrangers, des laboratoires publics ou privés. 


\title{
Application of the continuum shell finite element SHB8PS to sheet forming simulation using an extended large strain anisotropic elastic-plastic formulation
}

the date of receipt and acceptance should be inserted later

\begin{abstract}
This paper proposes an extension of the SHB8PS solid-shell finite element to large strain anisotropic elasto-plasticity, with application to several non-linear benchmark tests including sheet metal forming simulations. This hexahedral linear element has an arbitrary number of integration points distributed along a single line, defining the "thickness" direction; and to control the hourglass modes inherent to this reduced integration, a physical stabilization technique is used. In addition, the assumed strain method is adopted for the elimination of locking. The implementation of the element in Abaqus/Standard via the UEL user subroutine has been assessed through a variety of benchmark problems involving geometric non-linearities, anisotropic plasticity, large deformation and contact. Initially designed for the efficient simulation of elastic-plastic thin structures, the SHB8PS exhibits interesting potentialities for sheet metal forming applications - both in terms of efficiency and accuracy. The element shows good performance on the selected tests, including springback and earing predictions for Numisheet benchmark problems.
\end{abstract}

Keywords solid-shell element · reduced integration · physical stabilization · assumed strain method · elastic-plastic behavior · anisotropic plasticity $\cdot$ sheet metal forming $\cdot$ springback

\section{Introduction}

The need for large-scale computations together with advanced algorithms for geometric and material non-linear applications has motivated many researchers to develop elements that are simple and efficient. Considerable effort has been devoted, during the last two decades, to the development of eight-node solid-shell elements for modeling of thin structures. First approaches of this kind can be found in Domissy [13], Miehe [31], Hauptmann and Schweizerhof [20], and Sze and Yao [45]. As they use linear interpolation for efficiency reasons, these elements exhibit various locking phenomena which should be avoided in order to achieve the desirable degree of accuracy. Nevertheless, compared to conventional shell elements they have the following advantages.

The use of full three-dimensional constitutive laws, without plane-stress assumptions. Direct calculation of thickness variations, as based on physical nodes. The procedure for configuration update is simpler with no rotational degrees of freedom involved. Natural connection with classical solid elements since displacements are the only degrees of freedom. For sheet forming applications, key features like

F. Abed-Meraim

Laboratoire d'Étude des Microstructures et de Mécanique des Matériaux, LEM3, CNRS

Arts et Métiers ParisTech - Metz

4 rue A. Fresnel, 57078 Metz Cedex 03, France

Tel.: +33-3-87-37-54-79

Fax: +33-3-87-37-54-70

E-mail: farid.abedmeraim@ensam.eu 
the automatic consideration of double-sided contact, increased accuracy with only one layer of elements through the thickness, and full 3D stress tensor make these elements particularly attractive, as they allow much larger aspect ratios compared to conventional solid elements.

The reduced integration technique was the first successful solution to alleviate some locking pathologies. Finite elements using this method are very attractive due to their computational efficiency. Nevertheless, stabilization procedures are required in order to prevent the spurious zero-energy deformation modes (or hourglass modes) induced by this reduced integration. Initiated by the works of Zienkiewicz et al. [52], Hughes et al. [24] and Hughes [22], many authors have used this approach (e.g. Reese [35], Reese and Wriggers [37] and Reese et al. [38]).

In order to circumvent locking phenomena for three-dimensional low-order elements, several authors, like Bui et al. [9], Areias et al. [7] and Fontes Valente et al. [17], have used the enhanced assumed strain (EAS) method (or incompatible mode method), based on Simo and Rifai's pioneer work [44]. The basis of such element formulations is given by the mixed variational principle in which the so-called incompatible strain and stress act as additional independent variables. Recent investigations have combined EAS and reduced integration techniques to derive efficient and accurate elements. As examples, some authors used a fixed number of Gauss points in the thickness direction $[34 ; 36 ; 3 ; 5]$.

The assumed natural strain (ANS) method is one of the approaches used to cure transverse shear locking. This strategy has been used by Sze and Yao [45], Vu-Quoc and Tan [49] and Klinkel et al. [26] for fully integrated solid-shells. In recent contributions, Cardoso et al. [11], Schwarze and Reese [39; 40] and Schwarze et al. [41] have used both EAS and ANS approaches along with reduced integration.

The SHB8PS is one such element that has been recently developed $[1 ; 28 ; 2]$, based on reduced integration with eight physical nodes, but using an arbitrary number of integration points through the thickness direction. This avoids the use of several layers of elements in order to increase the number of thickness integration points, e.g. for metal forming problems. The approach combining the assumed strain method and reduced integration is adopted in order to eliminate locking problems. The hourglass modes caused by the in-plane reduced integration are efficiently controlled by a stabilization technique following the approach given by Belytschko and Bindeman [8].

The SHB8PS element was first developed within an explicit formulation and implemented into an explicit dynamic code (EUROPLEXUS) in order to simulate impact problems [1]. Later, an implicit version of the element was formulated and implemented into the quasi-static implicit code (INCA) for elastic-plastic stability applications [28; 2]. More recently, this version was implemented into the quasi-static implicit code (ASTER). In the current contribution, the solid-shell element SHB8PS is implemented into the commercial code (Abaqus/Standard) using the User Element subroutine UEL and coupled with a general, anisotropic elastic-plastic model [18]. The good performance of the element is demonstrated through non-linear benchmark problems involving large strains, plasticity and contact.

The outline of the paper is as follows. The formulation of the SHB8PS element is summarized in Section 2, including its physical stabilization. In Section 3, its formulation is extended to anisotropic elastic-plastic behavior models with combined isotropic-kinematic hardening at large deformations. Section 4 summarizes the implementation of the resulting element into the Abaqus/Standard code. To assess the effectiveness and performance of the element implementation, Section 5 is devoted to numerical examples dealing with geometric and material non-linear analyses as well as springback and earing predictions for Numisheet benchmark problems. Finally, some concluding remarks are drawn in Section 6 .

\section{Formulation of the SHB8PS element}

\section{$2.1 \mathrm{Hu}-$ Washizu variational principle}

As proposed by several authors (see e.g. [16]), the Hu-Washizu non-linear mixed variational principle is expressed by the equation:

$$
\delta \pi(\boldsymbol{v}, \dot{\bar{\varepsilon}}, \overline{\boldsymbol{\sigma}})=\int_{\Omega_{e}} \delta \dot{\bar{\varepsilon}}^{T} \cdot \boldsymbol{\sigma} d \Omega+\delta \int_{\Omega_{e}} \overline{\boldsymbol{\sigma}}^{T} \cdot\left(\nabla_{s}(\boldsymbol{v})-\dot{\bar{\varepsilon}}\right) d \Omega-\delta \dot{\mathbf{d}}^{T} \cdot \mathbf{f}^{e x t}=0
$$


where $\delta$ denotes a variation, $\boldsymbol{v}$ the velocity field, $\overline{\boldsymbol{\varepsilon}}$ the assumed strain rate, $\overline{\boldsymbol{\sigma}}$ the interpolated stress, $\boldsymbol{\sigma}$ the stress evaluated by the constitutive law, $\dot{\mathbf{d}}$ the nodal velocities, $\mathbf{f}^{\text {ext }}$ the external nodal forces and $\nabla_{s}(\boldsymbol{v})$ the symmetric part of the velocity gradient. The assumed strain formulation used to construct the SHB8PS element is a simplified form of the $\mathrm{Hu}$-Washizu variational principle as described by Simo and Hughes [42]. In this form the interpolated stress is assumed to be orthogonal to the difference between the symmetric part of the velocity gradient and the assumed strain rate, which gives

$$
\delta \pi(\dot{\bar{\varepsilon}})=\int_{\Omega_{e}} \delta \dot{\bar{\varepsilon}}^{T} \cdot \boldsymbol{\sigma} d \Omega-\delta \dot{\mathbf{d}}^{T} \cdot \mathbf{f}^{e x t}=0
$$

\subsection{Finite element interpolation}

SHB8PS is a hexahedral isoparametric element with eight nodes and linear interpolation. It has $n_{\text {int }}$ integration points chosen along the thickness direction $\zeta$ in the local coordinate frame. Fig. 1 shows the reference geometry of the element and the location of its integration points.

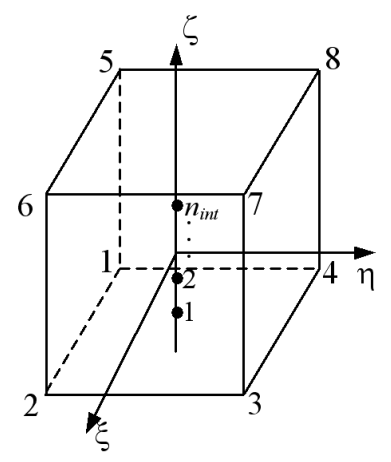

Fig. 1 SHB8PS reference geometry.

The spatial coordinates $x_{i}, i=1,2,3$, of any point in the element are related to the nodal coordinates $x_{i I}$ using the classic linear isoparametric shape functions $N_{I}(I=1, \ldots, 8)$

$$
x_{i}=x_{i I} N_{I}(\xi, \eta, \zeta)=\sum_{I=1}^{8} x_{i I} N_{I}(\xi, \eta, \zeta)
$$

Subscript $i$ varies from one to three and represents the direction of the spatial coordinates. Subscript $I$ varies from one to eight and corresponds to the nodes of the element. With the convention of implied summation for repeated indexes, which will be used hereafter, the displacement field $u_{i}$ within the element is expressed as a function of the nodal displacements $u_{i I}$ by

$$
u_{i}=u_{i I} N_{I}(\xi, \eta, \zeta)
$$

The strain (stored as a vector) can be related to the nodal displacements as

$$
\nabla_{s}(\mathbf{u})=\left[\begin{array}{c}
u_{x, x} \\
u_{y, y} \\
u_{z, z} \\
u_{x, y}+u_{y, x} \\
u_{y, z}+u_{z, y} \\
u_{x, z}+u_{z, x}
\end{array}\right]=\hat{\mathbf{B}} \cdot \mathbf{d}
$$

where $\hat{\mathbf{B}}$ is the modified discretized gradient operator (see [2]). 
2.3 Stabilization and assumed strain method

The operator $\hat{\mathbf{B}}$ enters the expression of the element stiffness matrix $\mathbf{K}_{e}$ :

$$
\mathbf{K}_{e}=\int_{\Omega_{e}} \hat{\mathbf{B}}^{T} \cdot \mathbf{C}^{e p} \cdot \hat{\mathbf{B}} d \Omega+\mathbf{K}_{G e o m}=\sum_{I=1}^{n_{\text {int }}} \omega\left(\zeta_{I}\right) J\left(\zeta_{I}\right) \hat{\mathbf{B}}^{T}\left(\zeta_{I}\right) \cdot \mathbf{C}^{e p}\left(\zeta_{I}\right) \cdot \hat{\mathbf{B}}\left(\zeta_{I}\right)+\mathbf{K}_{G e o m}
$$

In this equation, $J\left(\zeta_{I}\right)$ is the Jacobian, evaluated at the integration points, of the transformation between the unit reference configuration and the current configuration of an arbitrary hexahedron; $\omega\left(\zeta_{I}\right)$ is the corresponding weight, while $\mathbf{C}^{e p}=\frac{\partial \Delta \boldsymbol{\sigma}}{\partial \Delta \boldsymbol{\varepsilon}}$ is the elastic-plastic tangent modulus. The geometric stiffness matrix $\mathbf{K}_{\text {Geom }}$ originates from the linearization of the virtual work principle and is due to the non-linear (quadratic) part of the strain tensor. Its expression is derived in [2].

Note that two integration points are sufficient for dealing with elastic problems whereas a minimum of five integration points should be used when dealing with elastic-plastic applications, as it will be shown through the numerical examples in Section 5.

Whatever the number of integration points, their particular location along a line generates six so-called hourglass modes. These hourglass modes are characterized by a vanishing energy, while they should induce a non-zero strain. The control of the hourglass modes of the SHB8PS element is achieved by adding a stabilization component $\mathbf{K}_{\mathrm{STAB}}$ to the element stiffness matrix $\mathbf{K}_{e}$. This part is drawn from the work of Belytschko and Bindeman [8], who applied an efficient stabilization technique together with an assumed strain method. The stabilization forces are consistently derived in the same way. Moreover, the discretized gradient operator is projected onto an appropriate sub-space in order to eliminate shear and membrane locking.

Due to the particular location of the integration points, it can be shown that several terms of the $\hat{\mathbf{B}}$ operator vanish. In other words, the $\hat{\mathbf{B}}$ operator reduces to its $\hat{\mathbf{B}}_{12}$ part. Then, the remaining part $\hat{\mathbf{B}}_{34}$ of $\hat{\mathbf{B}}$ which vanishes at the integration points, is further projected as $\overline{\mathbf{B}}_{34}$ onto an appropriate sub-space (the full details of this decomposition can be found in [2]). The new operator can be written as

$$
\overline{\hat{\mathbf{B}}}=\hat{\mathbf{B}}_{12}+\overline{\hat{\mathbf{B}}}_{34}
$$

To take into account its contribution, the projected term $\overline{\mathbf{B}}_{34}$ is no longer evaluated at the integration points but using a specific co-rotational coordinate system in which analytical expressions are made possible. For the detailed expressions of operators $\hat{\mathbf{B}}_{12}$ and $\overline{\mathbf{B}}_{34}$ as well as the comprehensive derivation of hourglass modes and their stabilization stiffness matrix $\mathbf{K}_{\mathrm{STAB}}$, the reader can refer to reference [2].

By introducing the additive decomposition of the $\overline{\hat{\mathbf{B}}}$ operator, given in Eq. (7), into Eq. (6), the stiffness matrix becomes

$$
\mathbf{K}_{e}=\int_{\Omega_{e}} \overline{\hat{\mathbf{B}}}^{T} \cdot \mathbf{C}^{e p} \cdot \hat{\hat{\mathbf{B}}} d \Omega+\mathbf{K}_{G e o m}=\mathbf{K}_{12}+\mathbf{K}_{\mathrm{STAB}}+\mathbf{K}_{G e o m}
$$

where the first term $\mathbf{K}_{12}$ is evaluated at the integration points as

$$
\mathbf{K}_{12}=\int_{\Omega_{e}} \hat{\mathbf{B}}_{12}^{T} \cdot \mathbf{C}^{e p} \cdot \hat{\mathbf{B}}_{12} d \Omega=\sum_{I=1}^{n_{\text {int }}} \omega\left(\zeta_{I}\right) J\left(\zeta_{I}\right) \hat{\mathbf{B}}_{12}^{T}\left(\zeta_{I}\right) \cdot \mathbf{C}^{e p}\left(\zeta_{I}\right) \cdot \hat{\mathbf{B}}_{12}\left(\zeta_{I}\right)
$$

and $\mathbf{K}_{\mathrm{STAB}}$ represents the stabilization stiffness:

$$
\mathbf{K}_{\mathrm{STAB}}=\int_{\Omega_{e}} \hat{\mathbf{B}}_{12}^{T} \cdot \mathbf{C}^{e p} \cdot \overline{\hat{\mathbf{B}}}_{34} d \Omega+\int_{\Omega_{e}} \overline{\hat{\mathbf{B}}}_{34}^{T} \cdot \mathbf{C}^{e p} \cdot \hat{\mathbf{B}}_{12} d \Omega+\int_{\Omega_{e}} \overline{\hat{\mathbf{B}}}_{34}^{T} \cdot \mathbf{C}^{e p} \cdot \overline{\mathbf{B}}_{34} d \Omega
$$

The stabilization terms cannot be evaluated in a standard manner at the integration points, as they would vanish. Consequently, $\mathbf{K}_{\mathrm{STAB}}$ (as well as the corresponding stabilization forces) are rather calculated in a co-rotational coordinate system (see Belytschko and Bindeman [8]). Such a co-rotational approach has numerous advantages, including simplified expressions for the above stabilization stiffness matrix and a more effective treatment of shear locking in this frame. 
The stabilization stiffness matrix given in Eq. (10) is obtained analytically in the co-rotational system in the block-diagonal form

$$
\mathbf{K}_{\mathrm{STAB}}=\left[\begin{array}{ccc}
\mathbf{K}_{11} & \mathbf{0} & \mathbf{0} \\
\mathbf{0} & \mathbf{K}_{22} & \mathbf{0} \\
\mathbf{0} & \mathbf{0} & \mathbf{K}_{33}
\end{array}\right]
$$

The Young modulus $E$ and Poisson ratio $\nu$ enter the expressions of the $8 \times 8$ sub-matrices $\mathbf{K}_{i i}$, together with the nodal coordinates (see [2] for the complete details). However, this choice holds only for elastic behavior. In the case of elastic-plastic behavior, Young's modulus $E$ is no longer valid. Instead, a scalar modulus $E^{*}$ is defined, characteristic of the current tangent elastic-plastic stress-strain relationship. In this work, an average value is taken over the integration points across the thickness. This choice avoids an overstiff response that would correspond to a purely elastic hourglass stabilization scheme. This simple and robust approach provides a physical stabilization method without any tuning parameters, which effectively handles not only the dramatic change in stiffness due to the elastic-plastic transition, but also the intermediate situations where an arbitrary subset of integration points are in elastic state while the other ones are in plastic regime. Such configurations often occur during e.g. bending, multiplestep forming sequences, and springback. Bending-dominated applications are selected in Section 5 to validate this approach.

In a similar way, the internal forces of the element can be written as

$$
\mathbf{f}^{i n t}=\int_{\Omega_{e}} \overline{\hat{\mathbf{B}}}^{T} \cdot \boldsymbol{\sigma} d \Omega=\mathbf{f}_{12}^{i n t}+\mathbf{f}^{\mathrm{STAB}}
$$

where $\mathbf{f}_{12}^{\text {int }}$ is evaluated at the integration points in the conventional way

$$
\mathbf{f}_{12}^{i n t}=\int_{\Omega_{e}} \hat{\mathbf{B}}_{12}^{T} \cdot \boldsymbol{\sigma} d \Omega=\sum_{I=1}^{n_{\text {int }}} \omega\left(\zeta_{I}\right) J\left(\zeta_{I}\right) \hat{\mathbf{B}}_{12}^{T}\left(\zeta_{I}\right) \cdot \boldsymbol{\sigma}\left(\zeta_{I}\right)
$$

The second term $\mathbf{f}^{\mathrm{STAB}}$ represents the stabilization forces and depends on Young's modulus exactly like $\mathbf{K}_{\mathrm{STAB}}$ (see [2] for their exact expressions). Consequently, the same scalar elastic-plastic tangent modulus $E^{*}$ is consistently used in the expression of $\mathbf{f}^{\text {STAB }}$ for the stabilization of the SHB8PS element when coupled with elastic-plastic constitutive models. The details of this coupling are given in the following section.

\section{Constitutive equations}

\subsection{Incremental kinematics and local frames}

In the framework of the SHB8PS continuum shell element, three local frames are required to perform the entire calculations at the element level. All these local frames are orthogonal, and each of them is defined by means of a specific rotation matrix which refers to the common, global frame:

- The "element" frame, defined by rotation matrix $\mathbf{P}$, is calculated with respect to the coordinates of the element nodes [2]. The anisotropic elasticity matrix $\mathbf{C}^{\text {ele }}$ is expressed in this frame in order to approach plane-stress conditions:

$$
\mathbf{C}^{\text {ele }}=\left[\begin{array}{cccccc}
\bar{\lambda}+2 \mu & \bar{\lambda} & 0 & 0 & 0 & 0 \\
\bar{\lambda} & \bar{\lambda}+2 \mu & 0 & 0 & 0 & 0 \\
0 & 0 & E & 0 & 0 & 0 \\
0 & 0 & 0 & \mu & 0 & 0 \\
0 & 0 & 0 & 0 & \mu & 0 \\
0 & 0 & 0 & 0 & 0 & \mu
\end{array}\right]
$$

with $\bar{\lambda}=\frac{E \nu}{1-\nu^{2}}$ and $\mu=\frac{E}{2(1+\nu)}$. The choice of this constitutive matrix avoids locking phenomena encountered with a full three-dimensional law. 
- A "co-rotational" frame is used to calculate the stabilization stiffness $\mathbf{K}_{\mathrm{STAB}}$ and the stabilization forces $\mathbf{f}^{\mathrm{STAB}}$. The rotation matrix $\mathbf{R}$ that maps a vector from the global coordinate system to the co-rotational system is given in [2].

- Finally, a "material" frame must be introduced, in which the anisotropic plastic behavior is defined. A common choice to specify the rotation matrix $\mathfrak{R}$, which maps any vector or tensor from the global frame to the material frame, is by defining its rate as

$$
\dot{\mathfrak{R}}=\mathbf{W} \cdot \mathfrak{R}
$$

where $\mathbf{W}=(\nabla \boldsymbol{v})^{\text {asym }}$ is the spin tensor and [ ] $]^{\text {asym }}$ denotes the skew-symmetric part of a given tensor.

This particular choice corresponds to the use of the Jaumann objective rate in the constitutive model. As in the finite element framework, only discrete (incremental) values can be calculated for $\mathbf{W}$, Hughes and Winget [23] proposed to use the gradient of the displacement increment evaluated at the middle of the time step:

$$
\Delta \mathbf{W}=\left(\frac{\partial \Delta \mathbf{u}}{\partial \mathbf{x}_{t+\Delta t / 2}}\right)^{a s y m}
$$

where $\mathbf{x}_{t+\Delta t / 2}=\frac{1}{2}\left(\mathbf{x}_{t}+\mathbf{x}_{t+\Delta t}\right)$. Then, the rotation matrix $\Re$ is updated between stages $n$ and $n+1$ by

$$
\mathfrak{R}_{n+1}=\mathbf{r} \cdot \mathfrak{R}_{n}
$$

where the rotation increment $\mathbf{r}$ is calculated as

$$
\mathbf{r}=\left(\mathbf{I}-\frac{1}{2} \Delta \mathbf{W}\right)^{-1} \cdot\left(\mathbf{I}+\frac{1}{2} \Delta \mathbf{W}\right)
$$

Fig. 2 summarizes the different frames and rotation matrices used in this work. Any second-order tensor $\mathbf{a}^{\text {glo }}$ or fourth-order tensor $\mathbf{A}^{\text {glo }}$, defined in the global frame, becomes $\mathbf{a}^{\text {loc }}$, respectively, $\mathbf{A}^{\text {loc }}$ in a local frame defined by a rotation matrix $\mathbf{Q}$ according to the classic formulas

$$
\begin{gathered}
\mathbf{a}^{\text {loc }}=\mathbf{Q}^{T} \cdot \mathbf{a}^{\text {glo }} \cdot \mathbf{Q} \\
\mathbf{A}^{\text {loc }}=\mathbf{Q}^{T} \cdot \mathbf{Q}^{T} \cdot \mathbf{A}^{\text {glo }} \cdot \mathbf{Q} \cdot \mathbf{Q}
\end{gathered}
$$

Finally, the strain increment in the global frame is consistently calculated based on the same gradient of the displacement increment [23]:

$$
\Delta \varepsilon^{\text {glo }}=\left(\frac{\partial \Delta \mathbf{u}}{\partial \mathbf{x}_{t+\Delta t / 2}}\right)^{s y m}
$$

where [ ] $]^{\text {sym }}$ designates the symmetric part.

\subsection{Constitutive modeling}

The constitutive equations are written in a materially embedded coordinate system to ensure objectivity with respect to material rotation and to simplify the formulation and implementation of the material model. The constitutive equations were implemented in Abaqus/Standard using a UMAT-like subroutine (see [18]). This particular choice allows for a common implementation of new constitutive models in Abaqus/Standard either directly or by means of the user element SHB8PS via a UEL subroutine. On the other hand, this choice requires a rigorous separation of the element formulation, incremental kinematics and material-frame-based stress update. Also the specific continuum shell elasticity matrix must be taken into consideration in the constitutive algorithm. In the remaining of this section, all the tensor quantities are written in the material frame, unless specified otherwise. For the sake of simplicity, the "mat" superscript is omitted.

The rate of the Cauchy stress in the material, rotation-compensated frame, is given by the hypoelastic law

$$
\dot{\boldsymbol{\sigma}}=\mathbf{C}:\left(\mathbf{D}-\mathbf{D}^{p}\right)
$$




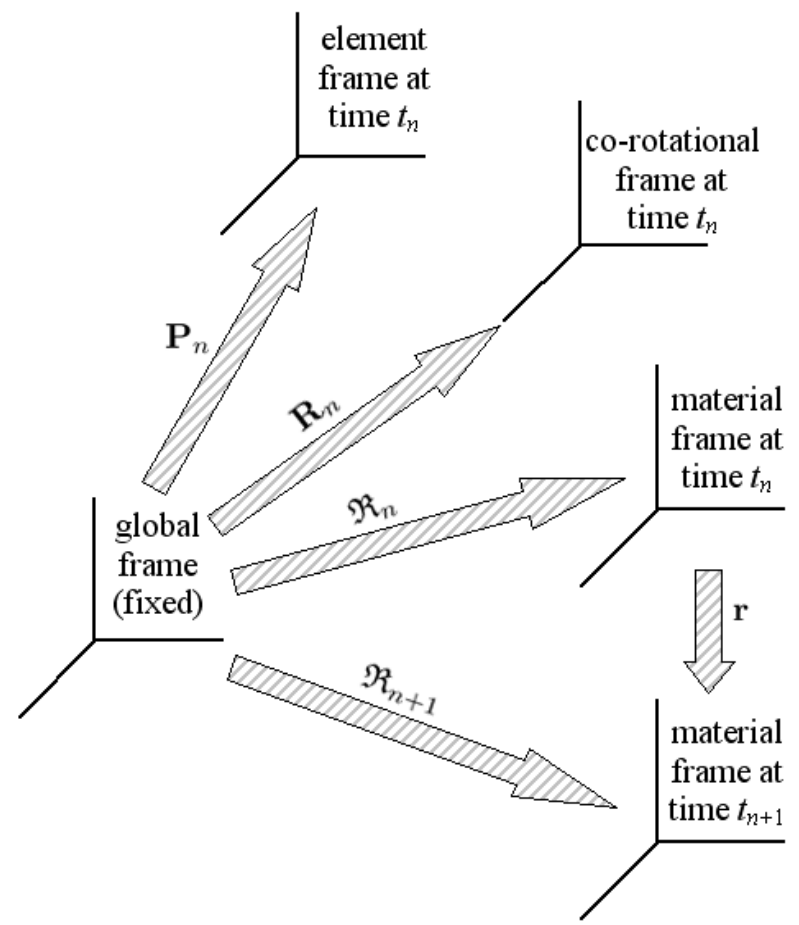

Fig. 2 Frames and rotation matrices used in the formulation of the SHB8PS element with anisotropic elasticplastic constitutive models.

where $\mathbf{C}$ is the anisotropic elasticity matrix (Eq. (14)) expressed in the material frame, while $\mathbf{D}$ and $\mathbf{D}^{p}$ are the strain rate tensor and plastic strain rate tensor, respectively.

The plastic strain rate tensor $\mathbf{D}^{p}$ is given by the flow rule

$$
\mathbf{D}^{p}=\dot{\lambda} \frac{\partial F}{\partial \boldsymbol{\sigma}}=\dot{\lambda} \mathbf{V}
$$

where $\mathbf{V}$ is the flow direction, normal to the yield surface defined by the potential $F$, and $\dot{\lambda}$ is the plastic multiplier to be determined from the consistency condition. The potential $F$ is given by

$$
F=\sigma_{e q}\left(\boldsymbol{\sigma}^{\prime}-\mathbf{X}\right)-Y \leq 0
$$

where $\sigma_{e q}$ is the equivalent stress, which is function of the deviatoric part $\boldsymbol{\sigma}^{\prime}$ of the Cauchy stress and the back-stress $\mathbf{X}$, whereas $Y$ is the current size of the yield surface; $\left(Y=Y_{0}+R, R\right.$ being the isotropic hardening variable). by

The quadratic Hill'48 yield surface [21] is used here. This plastic anisotropy description is defined

$$
\sigma_{e q}=\sqrt{\mathbf{T}: \mathbf{M}: \mathbf{T}}
$$

where $\mathbf{T}=\boldsymbol{\sigma}^{\prime}-\mathbf{X}$ is the deviatoric effective stress and $\mathbf{M}$ a fourth-order tensor containing the six anisotropy coefficients of Hill.

Isotropic and kinematic hardening are governed by the following generic equations

$$
\dot{Y}=H_{Y} \dot{\lambda}, \quad \dot{\mathbf{X}}=\mathbf{H}_{\mathbf{X}} \dot{\lambda}
$$

The consistency condition $\dot{F}=0$ leads to

$$
\dot{\lambda}=\frac{\mathbf{V}: \mathbf{C}: \mathbf{D}}{\mathbf{V}: \mathbf{C}: \mathbf{V}+\mathbf{V}: \mathbf{H}_{\mathbf{X}}+H_{Y}}
$$


The analytical elastic--plastic tangent modulus can then be deduced as

$$
\mathbf{C}^{e p}=\mathbf{C}-\alpha \frac{(\mathbf{C}: \mathbf{V}) \otimes(\mathbf{V}: \mathbf{C})}{\mathbf{V}: \mathbf{C}: \mathbf{V}+\mathbf{V}: \mathbf{H}_{\mathbf{X}}+H_{Y}}
$$

where $\alpha=1$ for plastic loading and 0 otherwise.

\subsection{Hardening models}

Numerous hardening models can be introduced in the general framework of phenomenological elastoplasticity. For any particular hardening model, one has to define functions $H_{Y}$ and $\mathbf{H}_{\mathbf{X}}$, respectively. Concerning isotropic hardening, in this work we use the non-linear models of Voce and Swift as well as the linear isotropic hardening model.

For consistency with Eq. (25), the rate form of Voce's law can be written as

$$
\dot{Y}=C_{R}\left(R_{\text {sat }}+Y_{0}-Y\right) \dot{\lambda}=H_{Y} \dot{\lambda}
$$

where $C_{R}$ characterizes the saturation rate of $Y$ and $Y_{0}+R_{s a t}$ its saturation value, while $Y_{0}$ is its initial value.

The Swift law is given by

$$
Y=K\left(\varepsilon_{0}+\varepsilon_{e q}^{p}\right)^{n}
$$

where $K, \varepsilon_{0}$ and $n$ are material parameters and $\varepsilon_{e q}^{p}$ is the equivalent plastic strain, with $\dot{\varepsilon}_{e q}^{p}=\dot{\lambda}$. Eq. (29) can be rewritten as

$$
\dot{Y}=n K^{\frac{1}{n}} Y^{\frac{n-1}{n}} \dot{\lambda}=H_{Y} \dot{\lambda}
$$

with $Y_{0}=K \varepsilon_{0}^{n}$.

Finally, the linear isotropic hardening model is given by the equation:

$$
Y=Y_{0}+H \varepsilon_{e q}^{p}
$$

or, similarly,

$$
\dot{Y}=H \dot{\lambda}=H_{Y} \dot{\lambda}
$$

The kinematic hardening can be described by a second-order tensorial variable $\mathbf{X}$, which allows the reproduction of the Bauschinger effect. The kinematic hardening defines a translation of the yield surface in the stress space. One can use the Armstrong-Frederick law described by

$$
\dot{\mathbf{X}}=C_{X}\left(X_{s a t} \mathbf{n}-\mathbf{X}\right) \dot{\lambda}=\mathbf{H}_{\mathbf{X}} \dot{\lambda}
$$

where $C_{X}$ and $X_{\text {sat }}$ are material parameters characterizing the saturation rate and saturation value of $\mathbf{X}$, respectively, while $\mathbf{n}=\frac{\mathbf{T}}{\sigma_{e q}}$ is the direction of the deviatoric effective stress.

These classic hardening models are adopted in this paper as they appear in the benchmark problems selected in Section 5. However, more advanced models have been implemented in the same framework, e.g. $[18 ; 19 ; 33]$. Virtually, any constitutive model implemented in a FE code via a UMAT-type user material subroutine can be implemented in the developed setting - provided that it may incorporate an anisotropic elasticity matrix. Alternatively, other continuum-type user elements can be coupled with the elasto-plastic constitutive models by means of the incremental kinematics framework described in this section. 


\section{Outline of the SHB8PS implementation in Abaqus/Standard}

In the following, the main steps of the non-linear implementation of the SHB8PS solid-shell element are summarized for completeness. The algorithm applies for all individual elements, at any time increment $\Delta t=t_{n+1}-t_{n}$.

Input: $\Delta t$

$\mathbf{x}, \Delta \mathbf{u}$ at the eight nodes

$\boldsymbol{\sigma}_{n}^{\text {glo }}, \mathfrak{R}_{n}, \mathbf{X}_{n}, R_{n}$ at the $n_{\text {int }}$ integration points

Output: $\mathbf{K}_{e}, \mathbf{f}^{\text {int }}$

$\boldsymbol{\sigma}_{n+1}^{\text {glo }}, \mathbf{C}_{e p}^{\text {glo }}, \Re_{n+1}, \mathbf{X}_{n+1}, R_{n+1}$ at the $n_{\text {int }}$ integration points

- Initialization: $\mathbf{K}_{12}=\mathbf{0}, \mathbf{f}_{12}^{\text {int }}=\mathbf{0}, \mathbf{K}_{\text {Geom }}=\mathbf{0}$

- Compute $\mathbf{C}^{\text {ele }}$

- For each integration point $\left(I=1, n_{\text {int }}\right)$

- Compute $\hat{\mathbf{B}}_{12}^{\text {glo }}, \nabla \Delta \mathbf{u}, \Delta \varepsilon^{\text {glo }}=(\nabla \Delta \mathbf{u})^{\text {sym }}, \Delta \mathbf{W}=(\nabla \Delta \mathbf{u})^{\text {asym }}$

- Compute rotation matrices:

$\mathbf{r}=\left(\mathbf{I}-\frac{1}{2} \Delta \mathbf{W}\right)^{-1} \cdot\left(\mathbf{I}+\frac{1}{2} \Delta \mathbf{W}\right)$

$\mathfrak{R}_{n+1}=\mathbf{r} \cdot \mathfrak{R}_{n}$

Compute $\mathbf{P}_{n}, \mathbf{R}_{n}$

- Rotation to material frame:

$\mathbf{C}^{\text {glo }}=\mathbf{P}_{n} \cdot \mathbf{P}_{n} \cdot \mathbf{C}^{\text {ele }} \cdot \mathbf{P}_{n}^{T} \cdot \mathbf{P}_{n}^{T}$

$\mathbf{C}^{\text {mat }}=\mathfrak{R}_{n+1}^{T} \cdot \mathfrak{R}_{n+1}^{T} \cdot \mathbf{C}^{\text {glo }} \cdot \mathfrak{R}_{n+1} \cdot \mathfrak{R}_{n+1}$

$\boldsymbol{\sigma}_{n}^{\text {mat }}=\mathfrak{R}_{n}^{T} \cdot \boldsymbol{\sigma}_{n}^{\text {glo }} \cdot \mathfrak{R}_{n}$

$\Delta \varepsilon^{\text {mat }}=\mathfrak{R}_{n}^{T} \cdot \Delta \varepsilon$ glo $\cdot \mathfrak{R}_{n}$

- Perform constitutive update: calculate $\mathbf{C}_{e p}^{\text {mat }}, \boldsymbol{\sigma}_{n+1}^{\text {mat }}, R_{n+1}, \mathbf{X}_{n+1}^{\text {mat }}$ (UMAT)

- Rotation to global frame:

$\boldsymbol{\sigma}_{n+1}^{\text {glo }}=\mathfrak{R}_{n+1} \cdot \boldsymbol{\sigma}_{n+1}^{\text {mat }} \cdot \mathfrak{R}_{n+1}^{T}$

$\mathbf{C}_{e p}^{\text {glo }}=\mathfrak{R}_{n+1} \cdot \mathfrak{R}_{n+1} \cdot \mathbf{C}_{e p}^{\text {mat }} \cdot \mathfrak{R}_{n+1}^{T} \cdot \mathfrak{R}_{n+1}^{T}$

- Update $\mathbf{K}_{12} \leftarrow \mathbf{K}_{12}+\omega\left(\zeta_{I}\right) J\left(\zeta_{I}\right)\left(\hat{\mathbf{B}}_{12}^{\text {glo }}\right)^{T} \cdot \mathbf{C}_{e p}^{\text {glo }} \cdot \hat{\mathbf{B}}_{12}^{\text {glo }}$

- Update $\mathbf{f}_{12}^{\text {int }} \leftarrow \mathbf{f}_{12}^{\text {int }}+\omega\left(\zeta_{I}\right) J\left(\zeta_{I}\right)\left(\hat{\mathbf{B}}_{12}^{\text {glo }}\right)^{T} \cdot \boldsymbol{\sigma}_{n+1}^{\text {glo }}$

- Update $\mathbf{K}_{\text {Geom }} \leftarrow \mathbf{K}_{\text {Geom }}+\omega\left(\zeta_{I}\right) J\left(\zeta_{I}\right) \mathbf{k}_{\text {Geom }}\left(\zeta_{I}\right)$

- Store internal variables $\boldsymbol{\sigma}_{n+1}^{\text {glo }}, \mathfrak{R}_{n+1}, \mathbf{X}_{n+1}, R_{n+1}$

- Compute $\mathbf{K}^{\mathrm{STAB}}$ and $\mathbf{f}^{\mathrm{STAB}}$

$-\mathbf{K}_{e}=\mathbf{K}_{12}+\mathbf{K}_{\text {Geom }}+\mathbf{K}^{\mathrm{STAB}}$

$-\mathbf{f}^{i n t}=\mathbf{f}_{12}^{i n t}+\mathbf{f}^{\mathrm{STAB}}$

The underlying modularity of the algorithm is well illustrated by the calculation of the elasticplastic tangent modulus $\mathbf{C}^{e p}$ involved in the expression of the stiffness matrix, Eqs. (6) and (8)(10). This algorithmic elastic-plastic tangent modulus is first calculated in the material frame, by consistent linearization of the rotation-compensated state update algorithm. Analytical expressions of the algorithmic (consistent) tangent modulus for backward Euler implicit time integration schemes have already been derived, e.g., in [18; 19; 33]. If an explicit time integration scheme is adopted instead, the analytical tangent modulus in Eq. (27) can be directly used. The resulting tensor is then pulled back into the global frame with the rotation matrix corresponding to the selected kinematics formulation. Note that one of the ingredients of the elastic-plastic tangent modulus, the elasticity matrix, incorporates the "numerical" elastic anisotropy due to the element formulation (see the expression of $\mathbf{C}^{\text {ele }}$, Eq. (14), defined in the element frame).

\section{Numerical examples}

In this section, the efficiency and accuracy of the SHB8PS element, implemented in Abaqus/Standard, are evaluated by analyzing five benchmark problems from literature. These numerical tests include geometric and material non-linearities (large strain anisotropic elasto-plasticity), contact as well as 
springback and earing predictions for Numisheet benchmark problems. The results are compared to solutions obtained by Abaqus elements. In the last two example problems, the results are additionally compared to experimental data.

Four finite elements from the element library of the Abaqus code are used in this work; these are:

- S4R: 4-node reduced-integration shell element.

- C3D8I: 8-node three-dimensional continuum element with incompatible modes.

- C3D8R: 8-node three-dimensional continuum element with reduced-integration.

- SC8R: 8-node reduced-integration continuum shell element.

The first two elements are state-of-the-art Abaqus shell and continuum elements, respectively. The last element is the continuum shell element recently made available in the code.

\subsection{Hinged elastic-plastic thin cylindrical roof}

This example concerns the instability behavior of a thin cylindrical roof. It has been considered by many authors in the case of elastic behavior $[12 ; 15 ; 25 ; 4]$. The geometry of the problem is illustrated in Fig. 3 and the geometric parameters are summarized in Table 1. The lateral straight sides are hinged $(u=v=w=0)$, while the curved sides are free. The roof is subjected to a concentrated load P applied at the center of the top surface. This problem is solved by the path-following Riks algorithm. Owing to symmetry, only one fourth of the roof was discretized. In the case of solid and solid-shell elements, two elements must be used along the thickness direction since the lateral straight sides are hinged on the midsurface nodes.

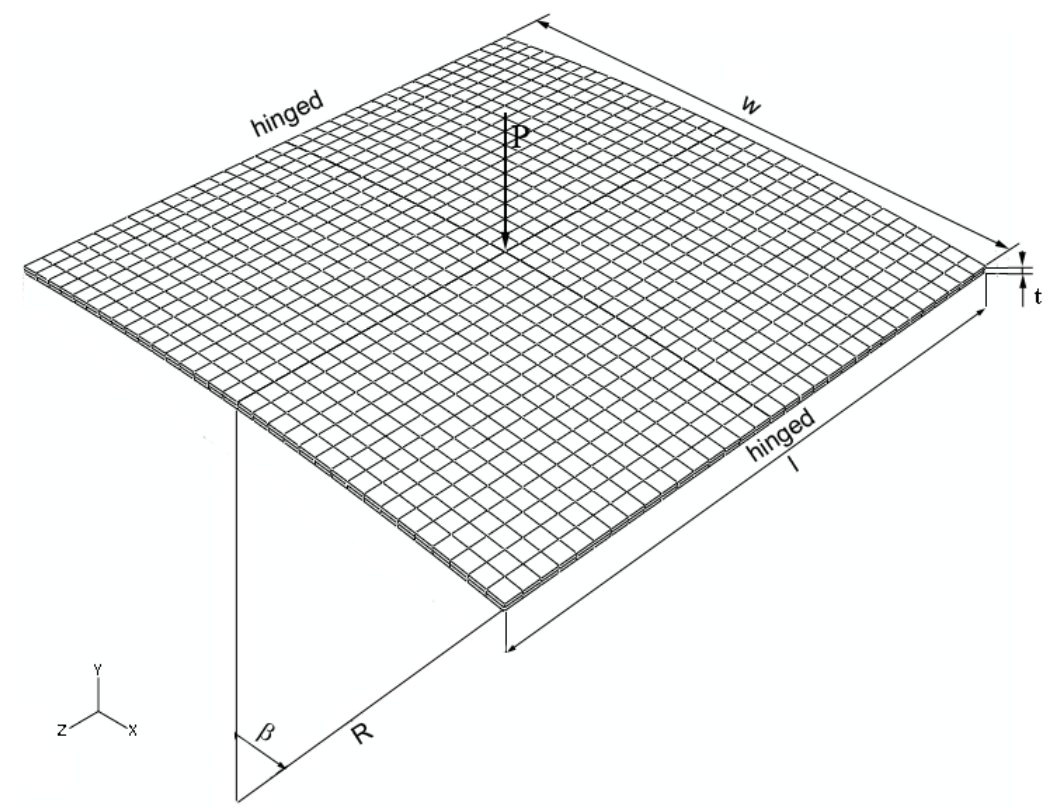

Fig. 3 Hinged thin cylindrical roof subjected to a central concentrated load: geometry and boundary conditions.

The material considered here is elastic-plastic with an elasticity modulus $E=3102.75 \mathrm{MPa}$, a Poisson coefficient $\nu=0.3$ and non-linear isotropic hardening given by the Voce's law (28). The material parameters for this test are given in Table 2. The numerical results for a mesh containing $32 \times 32 \times 2$ SHB8PS elements, given in terms of load versus displacement at the point where the load is applied, are depicted in Fig. 4. These results are compared to those obtained by using Abaqus elements with the discretizations: $32 \times 32$ S4R shell elements and $64 \times 64 \times 2$ SC8R solid-shell elements. Note that in this section, the reported results are the converged mesh solutions. In this first test, the curves 
Table 1 Geometric parameters of the hinged thin cylindrical roof.

\begin{tabular}{cccccc}
\hline length $l$ & width $w$ & thickness $t$ & radius $R$ & angle $\beta$ & load $P$ \\
\hline $508 \mathrm{~mm}$ & $507.15 \mathrm{~mm}$ & $6.35 \mathrm{~mm}$ & $2540 \mathrm{~mm}$ & $0.1 \mathrm{rad}$ & $1000 \mathrm{~N}$ \\
\hline
\end{tabular}

Table 2 Voce's material parameters for the hinged elastic-plastic thin cylindrical roof subjected to a central concentrated load.

\begin{tabular}{ccc|c|c|c}
\hline$E[\mathrm{MPa}$ & $\nu$ & $Y_{0}$ & {$[\mathrm{MPa}]$} & $R_{\text {sat }}[\mathrm{MPa}$ & $C_{R}$ \\
\hline 3102.75 & 0.3 & 27 & \multicolumn{2}{c}{2} & 2 \\
\hline
\end{tabular}

exhibit snap-through and snap-back behavior. Very good agreement between the solutions along the entire unstable load-displacement path is observed. In particular, the results of the SHB8PS element lay very close to those of the shell element, which should be the best suited classic element for this geometry. Note also that the convergence of the existing classic elements has been previously verified for these problems [27].

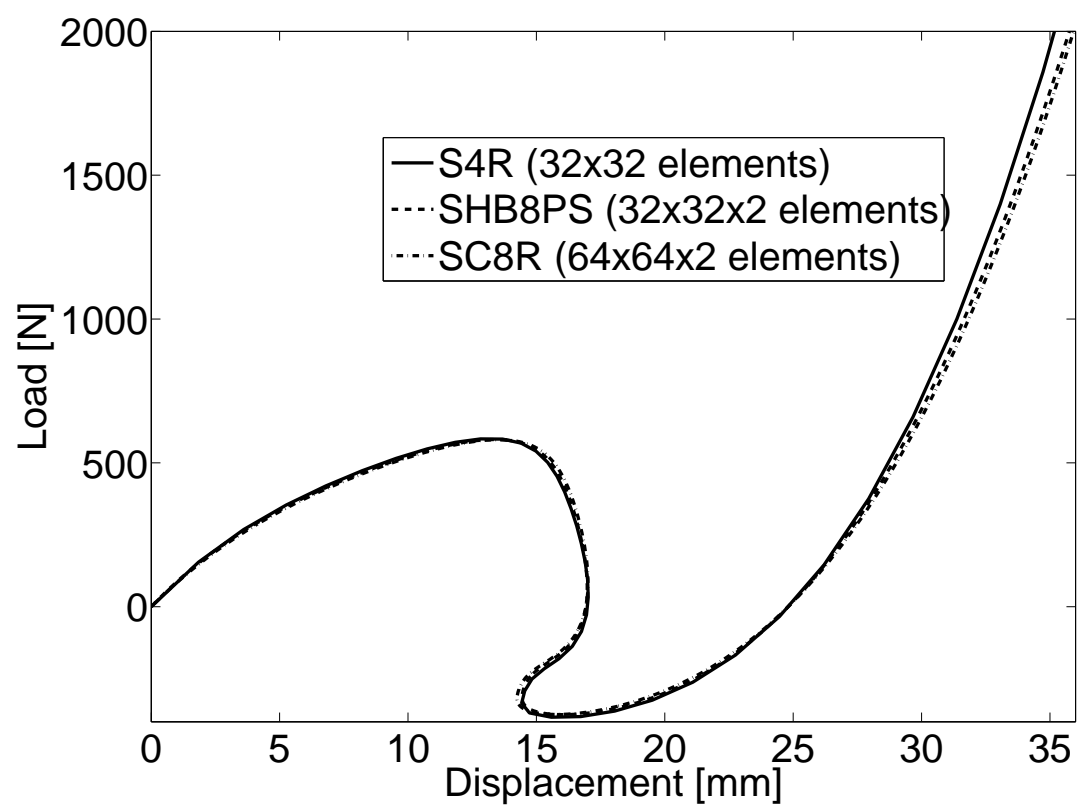

Fig. 4 Load-displacement curves for the hinged elastic-plastic thin cylindrical roof subjected to a central concentrated load.

Due to its particular geometry, this test is very sensitive to boundary conditions. In order to recover the solution found with shell elements, we had to employ two solid, respectively, solid-shell elements along the thickness and to hinge the lateral straight sides on the midsurface nodes. However, it would be more efficient to use a single continuum-type element through the thickness - especially continuum shell ones. In this case, the mesh no longer contains nodes on the mid-surface and boundary conditions would be applied either on the top or bottom layers. One should note that, in engineering practice, this would correspond very often to the boundary conditions actually applied to the real structure. Fig. 5 shows the load versus displacement curves for a mesh containing $32 \times 32 \times 2$ SHB 8 PS elements obtained when hinging the bottom edge (LBC) and the top edge (UBC), compared to the former reference solution (MBC). One can see that the difference is very important with varying the boundary conditions. One advantage of the continuum-type elements is that they allow for any of these three sets of boundary conditions, while shell elements are restricted to the mid-surface one. 


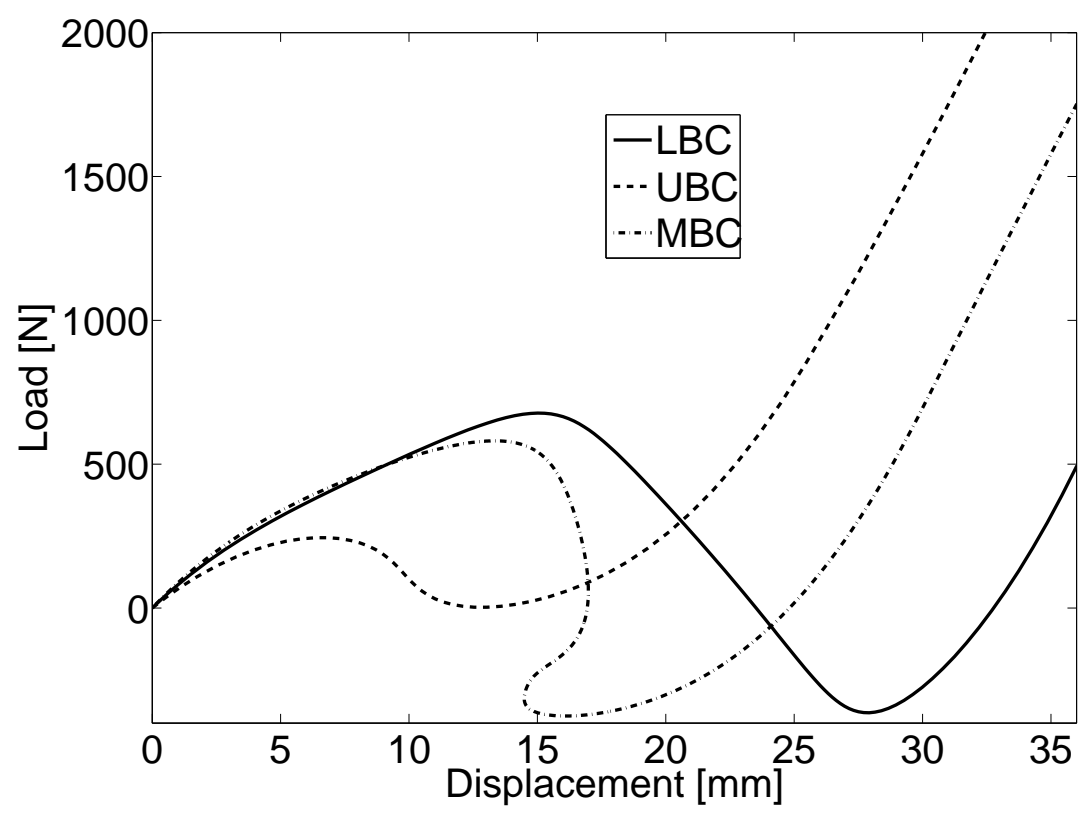

Fig. 5 Influence of the applied boundary conditions: Load-displacement curves for the hinged elastic-plastic thin cylindrical roof subjected to a central concentrated load for SHB8PS element.

Table 3 Voce's material parameters for the hinged elastic-plastic thick cylindrical roof subjected to a central concentrated load.

\begin{tabular}{ccc|c|c|c}
\hline$E[\mathrm{MPa}]$ & $\nu$ & $Y_{0}[\mathrm{MPa}]$ & $R_{\text {sat }}[\mathrm{MPa}]$ & $C_{R}$ \\
\hline 3102.75 & 0.3 & 15 & 9 & 2 \\
\hline
\end{tabular}

\subsection{Hinged elastic-plastic thick cylindrical roof}

Several authors $[46 ; 47 ; 48 ; 25]$ have emphasized the dramatic sensitivity of the previous test with respect to the thickness of the sheet. Indeed, doubling the thickness $(t=12.7 \mathrm{~mm})$ does not only increase the critical buckling loads, but also modifies the shape of the load-displacement curve as the snap-back phenomenon completely disappears. An elastic-plastic version of this test is considered here, with the material parameters given in Table 3. Similarly to the first test, the load versus displacement curves are compared for the discretizations containing $20 \times 20 \times 2$ SHB8PS elements, $20 \times 20$ S4R shell elements and $80 \times 80 \times 2$ SC8R solid-shell elements (see Fig. 6). The curves present the snap-through behavior typical for such limit-point buckling problems. The results of the SHB8PS element are in good agreement with those of Abaqus elements.

\subsection{Pinched cylinder at large elastic-plastic deformations}

In this example, the elastic-plastic deformation of a cylinder subjected to two opposite concentrated loads in the middle of the structure and bounded by rigid diaphragms on its extremities is considered. This problem has been investigated by a number of authors like [43;50;14;28].

The undeformed mesh and boundary conditions are shown in Fig. 7 . The geometry is characterized by the length $L=600 \mathrm{~mm}$, the radius $R=300 \mathrm{~mm}$ and thickness $t=3 \mathrm{~mm}$. Due to symmetry, only one eighth of the cylinder is discretized. At the ends of the cylinder, the rigid diaphragms prevent any displacement in the radial directions. Material properties are the elasticity modulus $E=3000 \mathrm{MPa}$, Poisson's coefficient $\nu=0.3$ and initial yield stress $Y_{0}=24.3 \mathrm{MPa}$. A linear isotropic hardening law is adopted as given in Eq. (31). The linear hardening coefficient $H$ is taken equal to $300 \mathrm{MPa}$. 


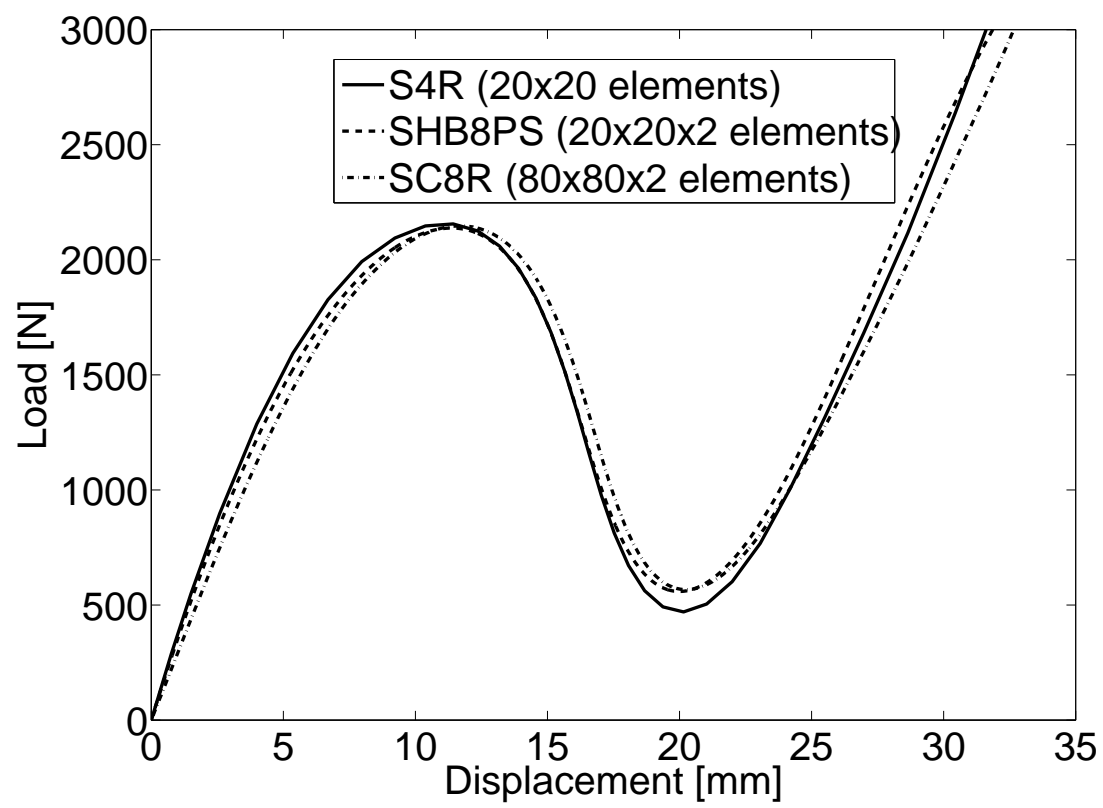

Fig. 6 Load-displacement curves for the hinged elastic-plastic thick cylindrical roof subjected to a central concentrated load.

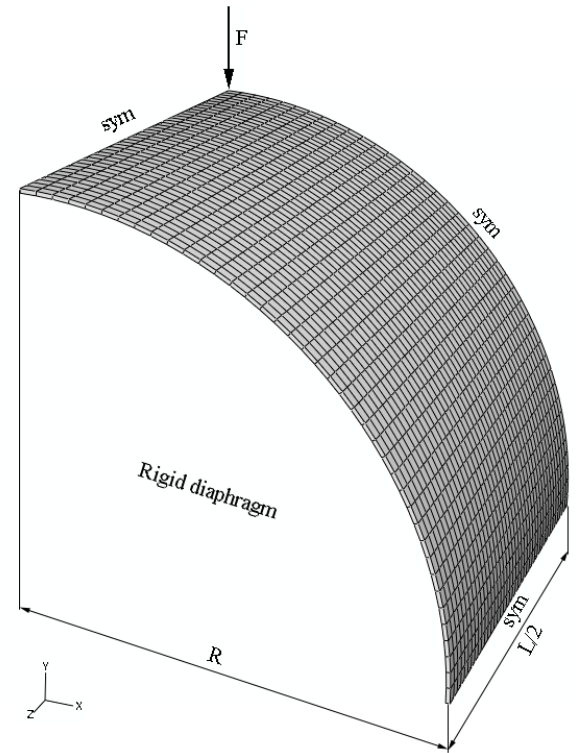

Fig. 7 Geometry and boundary conditions for the pinched cylinder.

Fig. 8 depicts the load-deflection curves. For the same mesh $(40 \times 40 \times 1$ elements $)$, the results of the SHB8PS solid-shell element are compared to those of the SC8R solid-shell element and the S4R shell element, along with the reference solutions obtained by Wriggers et al. [50] and Eberlein and Wriggers [14]. The calculations using the S4R element failed at a certain loading level, while the SC8R element is too stiff in this test problem and also converges more slowly. For this particularly discriminating test, the curve using SHB8PS element is clearly in better agreement with the 3D investigations of Wriggers et al. [50] and Eberlein and Wriggers [14]. 


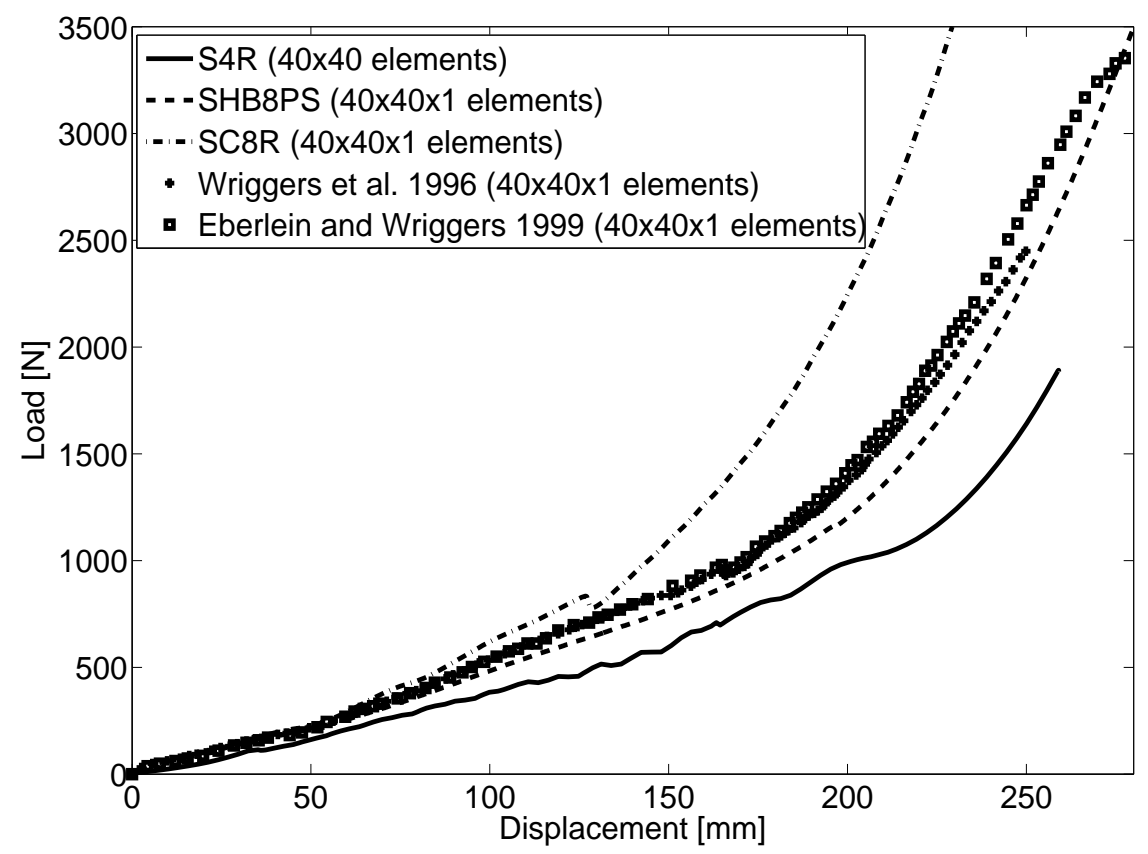

Fig. 8 Load-deflection curves for the elastic-plastic pinched cylinder.

\subsection{Unconstrained cylindrical bending}

In this section, the example of the unconstrained cylindrical bending test proposed as springback benchmark in Numisheet 2002 [32] is investigated to assess the performance of the SHB8PS element in presence of geometric, material and contact non-linearities. This test has been considered in several references like in $[51 ; 29 ; 10 ; 6]$. This benchmark involves a bending-dominated deformation since there is no blank holder. The problem has complex contact boundary conditions during the forming process and the springback after forming is severe.

The schematic view of the problem is illustrated in Fig. 9. Following [32], the geometric parameters are summarized in Table 4. Both an Aluminum Alloy 6111-T4 and a High strength steel were investigated in this benchmark. The materials are supposed elastic-plastic with isotropic hardening following Swift law given by Eq. (30). The material properties of Aluminum 6111-T4 and High strength steel as well as the Coulomb friction coefficient of the interaction of the surfaces punch-sheet and die-sheet are given in Table 5 .

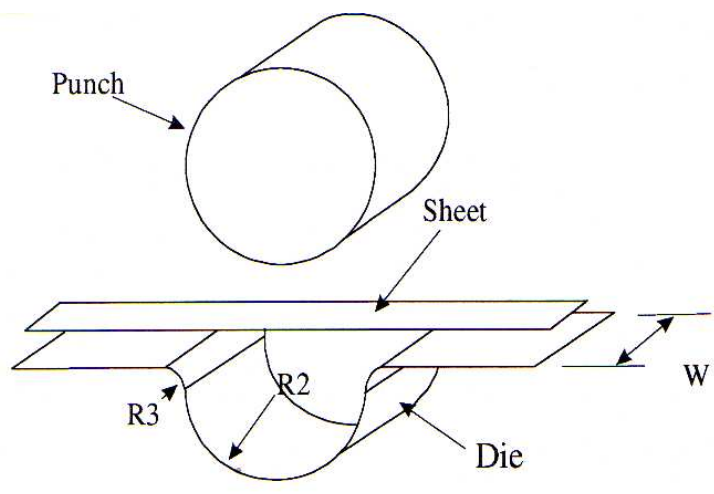

Fig. 9 Tool geometry for the unconstrained bending problem. 
Table 4 Geometric parameters of the unconstrained cylindrical bending problem.

\begin{tabular}{lc|lc}
\hline Geometric parameter & {$[\mathrm{mm}]$} & Geometric parameter & $\mathrm{mm}]$ \\
\hline Punch radius & 23.5 & Length of the sheet & 120.0 \\
\hline Die radius (R2) & 25.0 & Thickness of the sheet & 1.0 \\
\hline Die shoulder (R3) & 4.0 & Width of the sheet & 30.0 \\
\hline Width of tools (W) & 50.0 & Punch stroke & 28.5 \\
\hline
\end{tabular}

Table 5 Material properties of the used materials for the unconstrained cylindrical bending problem.

\begin{tabular}{ccccccc}
\hline Material & $\begin{array}{c}\text { Young } \\
E \text { odulus } \\
E[\mathrm{MPa}]\end{array}$ & $\begin{array}{c}\text { Poisson } \\
\text { ratio } \nu\end{array}$ & $K[\mathrm{MPa}]$ & $\mathrm{n}$ & $\varepsilon_{0}$ & $\begin{array}{c}\text { Friction } \\
\text { coefficient } \\
\mu\end{array}$ \\
\hline $\begin{array}{c}\text { Aluminum } \\
6111-\mathrm{T} 4\end{array}$ & $7.05 \times 10^{4}$ & 0.342 & 550.40 & 0.22300 & 0.0093 & 0.13480 \\
\hline $\begin{array}{c}\text { High } \\
\text { strength } \\
\text { steel }\end{array}$ & $2.175 \times 10^{5}$ & 0.300 & 645.24 & 0.25177 & 0.0102 & 0.14812 \\
\hline
\end{tabular}

The amount of springback is quantified by the angle $\theta$ as defined in Fig. 10. This angle is measured after forming at the maximum punch displacement and after springback. The tools are defined as analytical rigid surfaces.

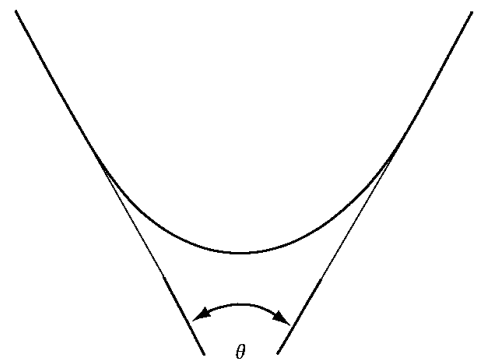

Fig. 10 Definition of the angle to measure springback for the unconstrained cylindrical bending problem.

The SHB8PS element is compared with Abaqus solid and shell elements. Indeed, it is well-known that in applications of sheet metal forming, shell elements have difficulties in dealing with doublesided contact - while conventional solid elements necessitate several element layers to capture bending effects. In the present work, the simulations carried out with the SHB8PS element use only one element layer through the thickness, with several integration points. For symmetry reasons, only one quarter of the blank is discretized by means of 150 SHB8PS elements in the length and only one element over the width of the sheet. Unless otherwise specified, the analysis with the SHB8PS element is performed using five Gauss points in the thickness direction.

\subsubsection{Contact treatment}

Abaqus capabilities are limited inasmuch user elements cannot be part of a contact surface. To overcome this limitation, two techniques have been used to deal with contact when the SHB8PS element, implemented in Abaqus through the UEL interface, must form part of the contact surface. The first one, called the overlay element technique consists in superimposing three-dimensional Abaqus elements with SHB8PS ones. These elements share the same nodes as SHB8PS elements; they have a negligible stiffness and their role is to deal with contact. This technique also allows for the visualization of the deformed mesh, but it induces a slightly modified rigidity and requires additional CPU time.

The second possibility is to use surface elements. It consists in superimposing Abaqus surface elements to the SHB8PS faces that are in contact with the tools. These elements share the same nodes as SHB8PS elements. The Abaqus surface elements have zero rigidity and they only handle the contact 
Table 6 Simulated opening angles before and after springback by using SHB8PS element for High Strength Steel and Aluminum 6111-T4: comparison of contact techniques.

\begin{tabular}{c|cc}
\hline \multicolumn{3}{|c}{ High Strength Steel } \\
\hline & $\begin{array}{c}\text { Overlay element } \\
\text { technique }\end{array}$ & $\begin{array}{c}\text { surface element } \\
\text { technique }\end{array}$ \\
\hline forming & 23.0692 & 22.8231 \\
\hline springback & 36.3952 & 36.3000 \\
\hline \multicolumn{3}{|c}{ Aluminum 6111-T4 } \\
\hline forming & 22.3336 & 22.1607 \\
\hline springback & 62.9229 & 62.8598 \\
\hline
\end{tabular}

constraints. This technique does not allow for the visualization of the deformed mesh with the Abaqus built-in postprocessor.

Fig. 11 compares the punch force-displacement curves for the two contact techniques. At the beginning, the punch force increases linearly due to the elastic response of the sheet metal. After the plastic deformation has been started, the slope decreases and becomes negative by the end of the process as the sheet is completely bent. Table 6 compares the opening angles before and after springback. The simulated values for the two techniques are almost identical both in terms of loaddisplacement predictions and opening angles. The CPU time is $20 \%$ higher in the case of the overlay element technique. In the following, the overlay element technique is used because it enables the visualization of the deformed mesh with Abaqus postprocessor.

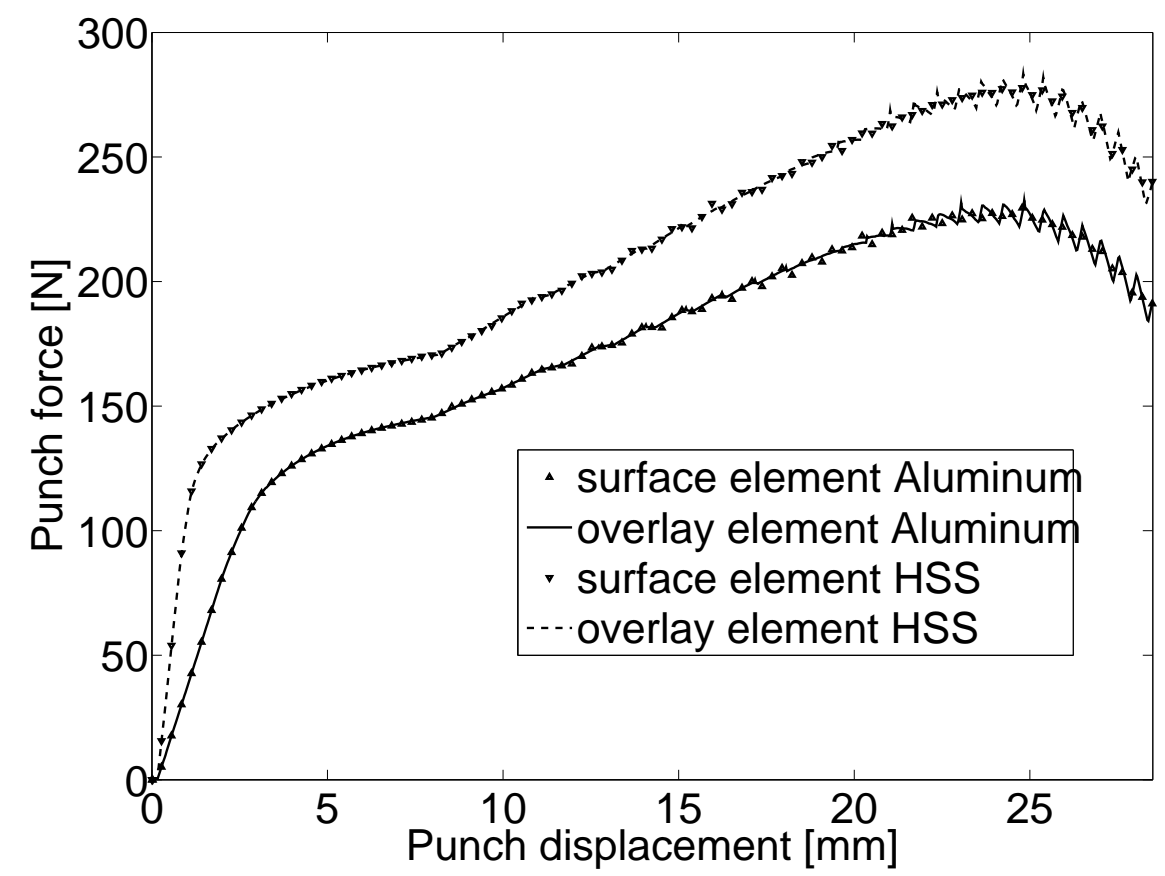

Fig. 11 Punch force vs. punch displacement plots for Aluminum 6111-T4 and High Strength Steel (HSS): comparison of contact techniques.

\subsubsection{Comparison with Abaqus elements and experiment}

In order to validate the proposed solid-shell element, its predictions are compared to the experimental results of the Numisheet 2002 benchmarks for the two materials. The S4R and C3D8I elements are 
also used in the comparison. Again, 150 uniformly distributed elements are used in the length direction for the three elements. However, two layers of C3D8I elements are required in the thickness direction in order to represent the stress distribution due to bending with sufficient accuracy. Also, ten C3D8I elements are used along the width direction in order to keep their aspect ratio in acceptable limits. Note that five integration points were used for S4R and SHB8PS. Figs. 12 and 13 display the punch force versus punch displacement curves predicted by the three elements, along with the experimental results from Meinders et al. [30]. Results of four experiments (denoted BE-1, .., BE-4) are reported by Meinders et al. [30]. As illustrated in Fig. 12, slight differences - up to 15\% - appear between the different experiments. Consequently, the experimental curve represented for the Aluminum alloy (Fig. 13) is an average of the available experiments.

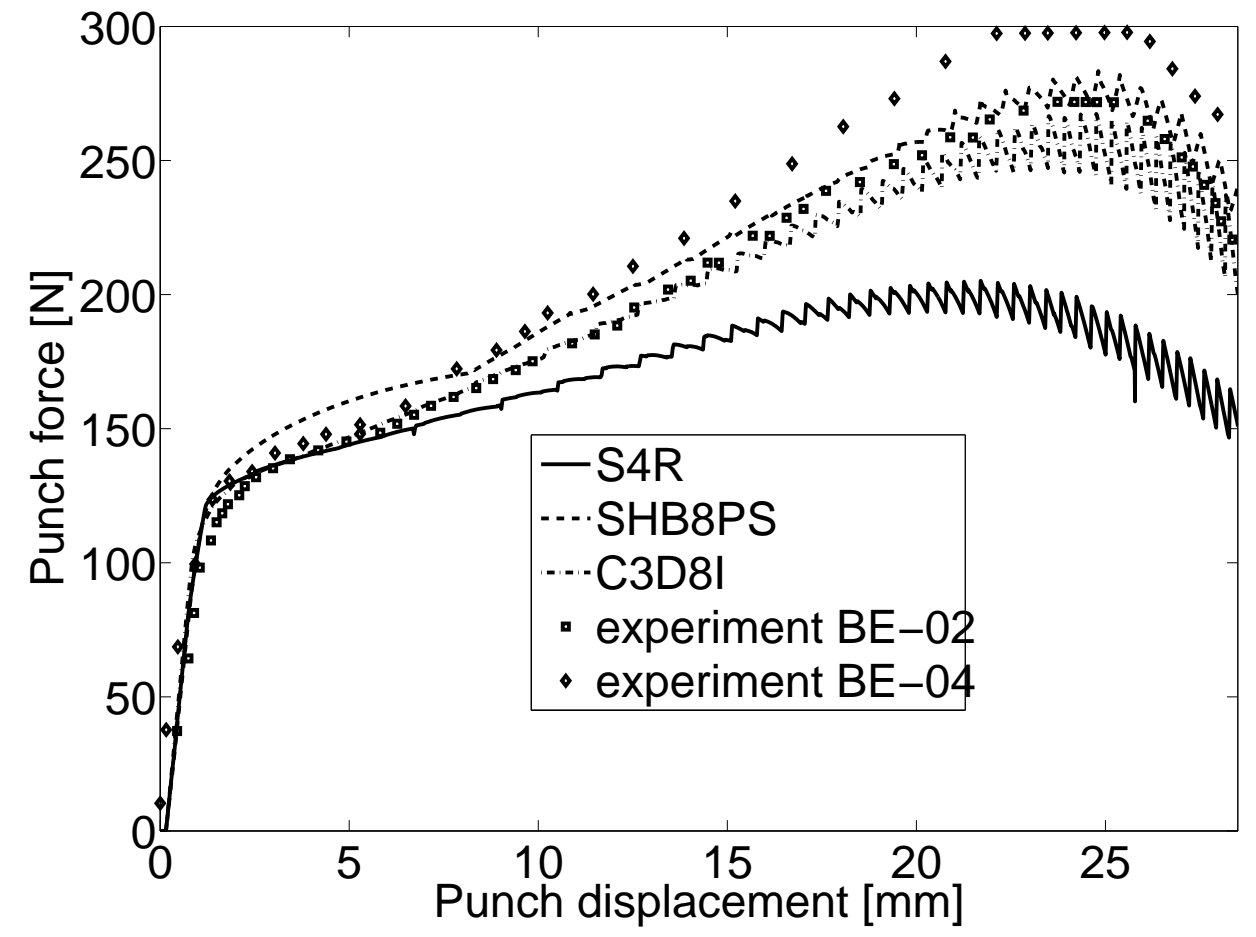

Fig. 12 Punch force vs. punch displacement plots for High Strength Steel.

Figs. 12 and 13 show that the numerical results obtained with SHB8PS element are the closest to the experimental results and they lay close to the solid element predictions. The slight differences between the two may be due to the different number and distribution of integration points along the thickness direction; this issue will be addressed in Section 5.4.3.

The springback angles are also investigated, as they were also experimentally measured [30]. The springback phenomenon is particularly exacerbated in this unconstrained bending application, as illustrated in Fig. 14. Table 7 summarizes the opening angles before and after springback for elements SHB8PS, C3D8I and S4R, compared to experiments. The simulated values with SHB8PS and C3D8I elements are close to each other and the closest to experiments. Comparing the numerical results to the experimental ones, the good performance of the SHB8PS solid-shell element is once again confirmed.

\subsubsection{Influence of the number of integration points through the thickness}

For elastic applications, two integration points over the thickness are sufficient to model bending problems, as the through-thickness stress distribution is linear. However, elastic-plastic applications 


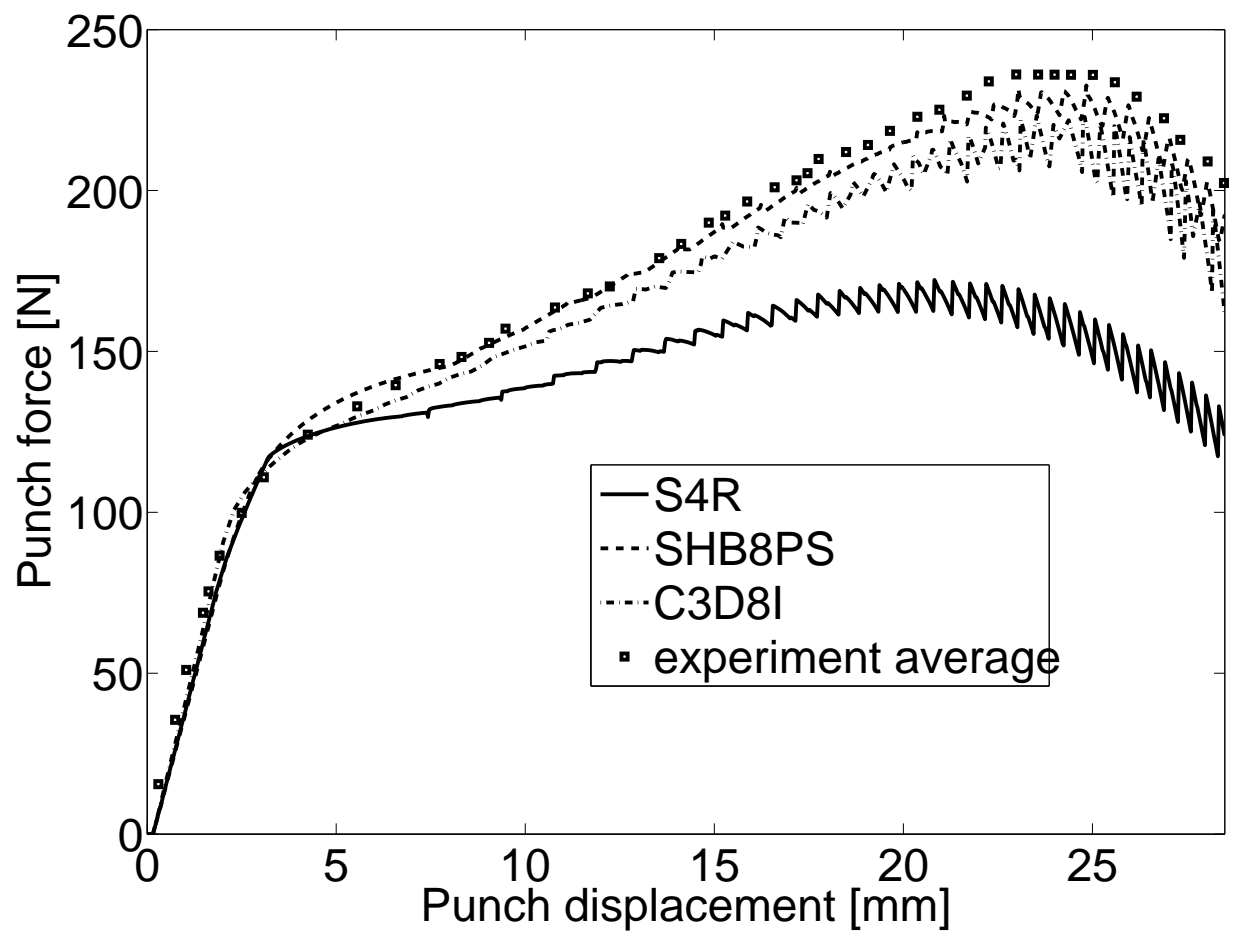

Fig. 13 Punch force vs. punch displacement plots for Aluminum 6111-T4.

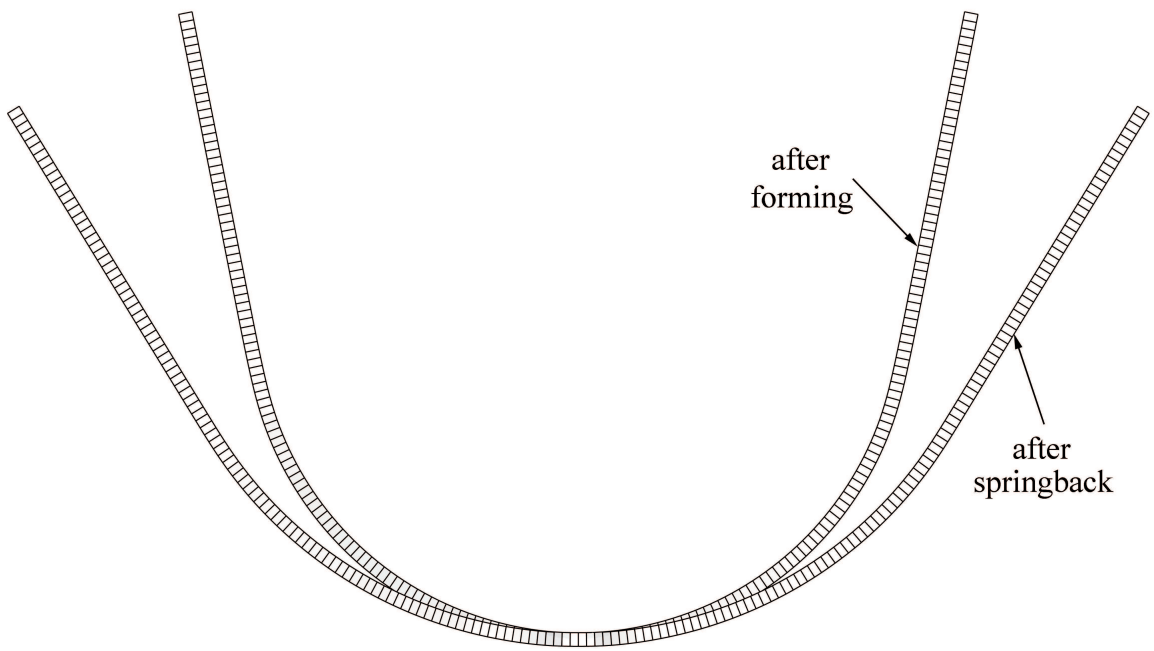

Fig. 14 Deformed shape of the sheet in the unconstrained bending problem.

need more integration points to describe the strongly non-linear through-thickness stress distribution. Several authors, like Abed-Meraim and Combescure [2], showed that, in general, five integration points in minimum are required to provide an accurate response in elastic-plastic problems.

The impact of the number of integration points is briefly investigated here as it may induce slight differences between predictions of different elements. A finer mesh is used for this analysis (300 elements in the length direction) so that the oscillations of the punch load, due to the contact evolution, are eliminated. Figs. 15 and 16 show the punch force vs. the punch displacement curves for SHB8PS element with varying the number of Gauss points through the thickness for both High Strength Steel 
Table 7 Measured and simulated opening angles before and after springback for High Strength Steel and Aluminum 6111-T4.

\begin{tabular}{|c|c|c|c|c|c|c|c|}
\hline \multicolumn{8}{|c|}{ High Strength Steel } \\
\hline & \multicolumn{4}{|c|}{ experimental } & \multicolumn{3}{|c|}{ simulated } \\
\hline & BE-01 & BE-02 & BE-03 & BE-04 & SHB8PS & C3D81 & S4R \\
\hline forming & 22.7707 & 22.0064 & 23.0255 & 20.8599 & 23.0692 & 22.5820 & 33.3078 \\
\hline springback & 37.4212 & 35.6787 & 30.9036 & 35.3636 & 36.3952 & 32.0832 & 43.9071 \\
\hline \multicolumn{8}{|c|}{ Aluminum 6111-T4 } \\
\hline forming & 21.0061 & 21.0061 & 19.4817 & 19.6341 & 22.3336 & 21.9577 & 32.5502 \\
\hline springback & 55.7784 & 54.4311 & 55.1796 & 53.5329 & 62.9229 & 54.8291 & 66.8663 \\
\hline
\end{tabular}

Table 8 Simulated opening angles before and after springback by using SHB8PS element for High Strength Steel and Aluminum 6111-T4: variation of the number of integration points through the thickness.

\begin{tabular}{c|ccccc}
\hline \multicolumn{7}{c}{ High Strength Steel } \\
\hline & $\begin{array}{c}2 \text { Gauss } \\
\text { points }\end{array}$ & $\begin{array}{c}\text { 3 Gauss } \\
\text { points }\end{array}$ & $\begin{array}{c}5 \text { Gauss } \\
\text { points }\end{array}$ & $\begin{array}{c}\text { 7 Gauss } \\
\text { points }\end{array}$ & $\begin{array}{c}9 \text { Gauss } \\
\text { points }\end{array}$ \\
\hline forming & 23.1956 & 23.1073 & 23.1301 & 23.1289 & 23.1266 \\
\hline springback & 38.8581 & 35.3352 & 36.3560 & 36.6505 & 36.7748 \\
\hline \multicolumn{7}{c}{ Aluminum } & $6111-T 4$ \\
\hline forming & 22.2996 & 22.4240 & 22.3557 & 22.3265 & 22.3107 \\
\hline springback & 70.3063 & 59.8636 & 62.8028 & 63.6647 & 64.0352 \\
\hline
\end{tabular}

and Aluminum 6111-T4, respectively. As expected, the elastic part of the curve is already well described with only two Gauss points. However, two Gauss points and three Gauss points over- and underestimate the punch force, respectively, in the elastic-plastic range. The curves converge with increasing the number of integration points. For the problem at hand, five integration points already provide a good approximation - thus validating the previous analyses. This choice has also been made in order to minimize the number of solid element layers used for comparison. Table 8 summarizes the influence of the through-thickness integration points on the forming and springback angles. These results are consistent with the conclusions previously drawn for the load--displacement predictions.

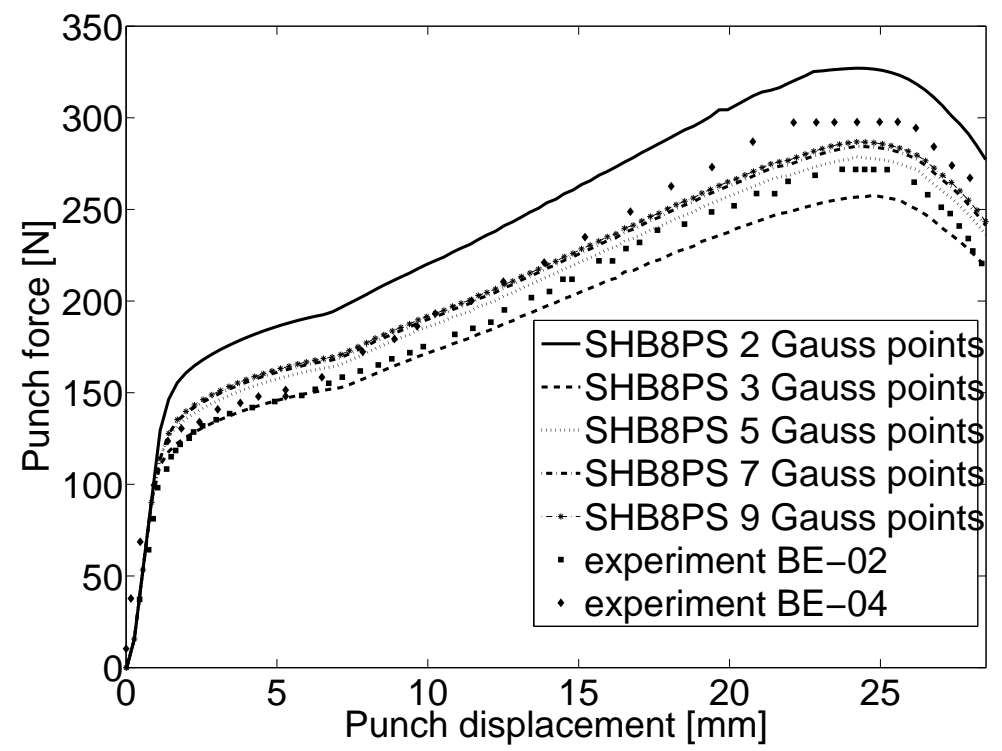

Fig. 15 Punch force vs. punch displacement plots for High Strength Steel: influence of the number of integration points through the thickness. 


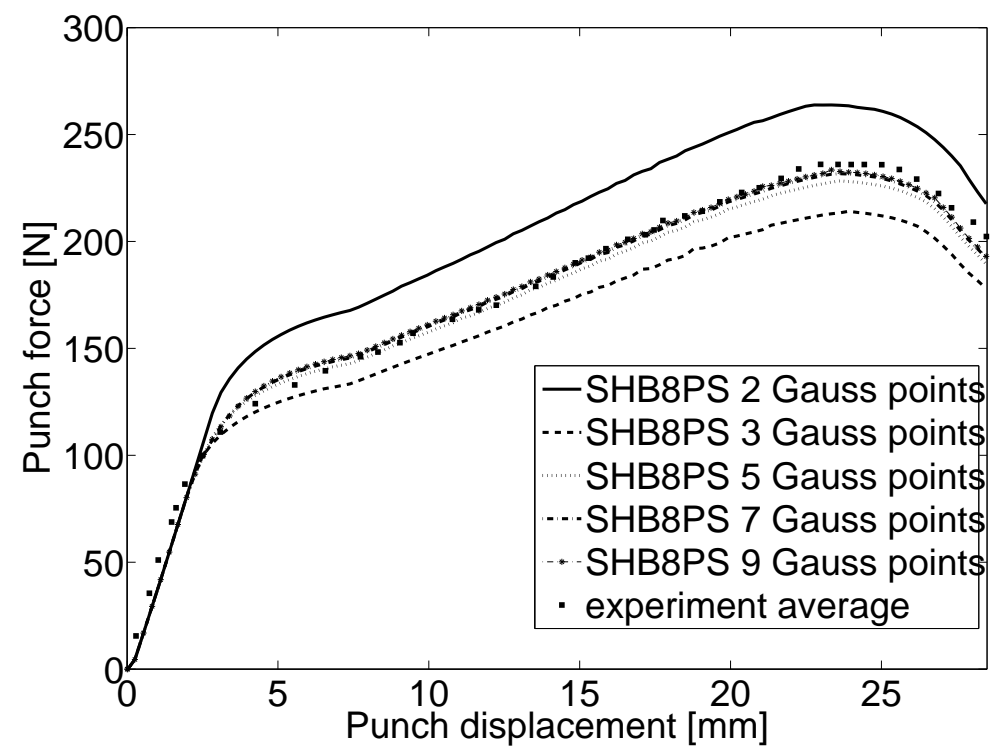

Fig. 16 Punch force vs. punch displacement plots for Aluminum 6111-T4: influence of the number of integration points through the thickness.

\subsection{Cylindrical cup drawing test}

In this example, the cylindrical cup drawing test, proposed at Numisheet 2002 as benchmark Test A [32], is used to investigate the earing evolution after forming when anisotropic behavior is considered for the Aluminum alloy 6111-T4. This problem is commonly considered for an assessment of the planar anisotropy via the earing profile along the rim of the cup after forming. Since a constant blank holding force is applied during the cup forming, it is a typical double-sided contact problem.

The schematic view of the problem is illustrated in Fig. 17 and the corresponding dimensions are given in Table 9. The material parameters of Aluminum 6111-T4 are given in Table 5 (section 5.4) where Swift's law is considered to describe the isotropic hardening. The plastic anisotropy behavior has been considered in this benchmark and the three r-values used to identify Hill's quadratic yield criterion are summarized in Table 10 . A constant $50 \mathrm{kN}$ blank holder force is applied during the forming process. The earing pattern is measured by the radial distance from the center to the outer edge of the cup at different angles, at the final punch displacement of $40 \mathrm{~mm}$.

Table 9 Geometric parameters of the cylindrical cup drawing setup.

\begin{tabular}{ll|l|l}
\hline Geometric parameter & $\mathrm{mm} \mid$ & Geometric parameter & $\mathrm{mm} \mid$ \\
\hline Punch diamater $\left(D_{p}\right)$ & 100.0 & Punch profile radius $\left(r_{p}\right)$ & 9.5 \\
\hline Die opening diameter $\left(D_{d}\right)$ & 102.5 & Die profile radius $\left(r_{d}\right)$ & 7.0 \\
\hline Blank diameter $\left(D_{b}\right)$ & 180.0 & Thickness of the sheet & 1.0 \\
\hline
\end{tabular}

Table 10 r-values for Al6111-T4 Aluminum alloy sheet.

\begin{tabular}{cc}
\hline $\begin{array}{c}\text { Angle } \theta \text { (deg.) from } \\
\text { rolling direction }\end{array}$ & r-value \\
\hline $0^{\circ}$ & 0.894 \\
\hline $45^{\circ}$ & 0.611 \\
\hline $90^{\circ}$ & 0.660 \\
\hline
\end{tabular}




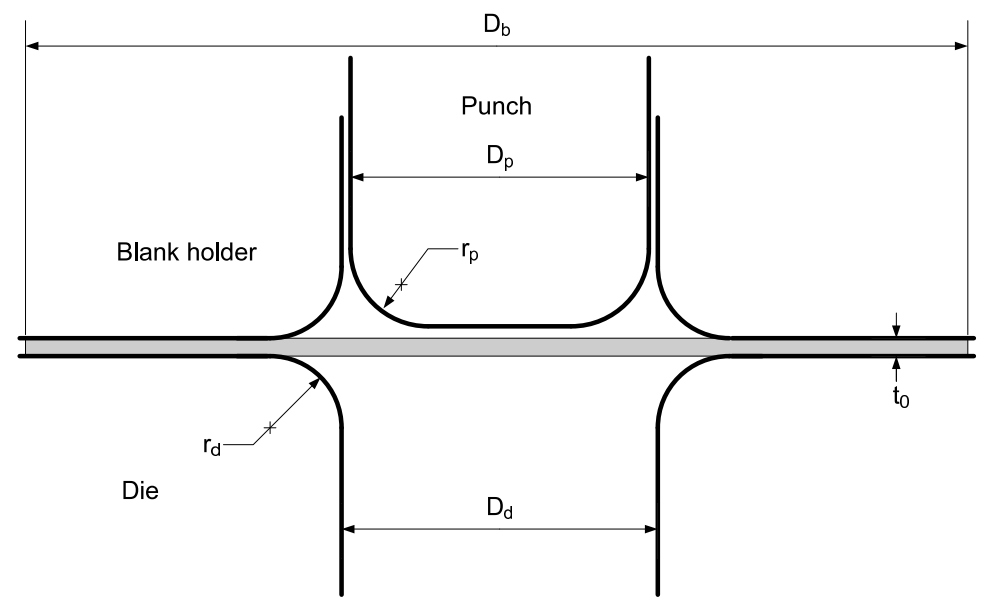

Fig. 17 Cylindrical cup drawing set-up.

The tools are modeled as rigid bodies. Due to the problem symmetry, only a quarter of the sheet was modeled with a total of 900 elements (see Fig. 18). Note that five through-thickness integration points were used in the simulations with SHB8PS. For the contact, the first technique described in section 5.4.1 is used to ensure the contact between the blank and the tools with a Coulomb friction coefficient equal to 0.0096 [32]. The simulations are compared to the experimental data reported in Numisheet 2002 benchmark A.

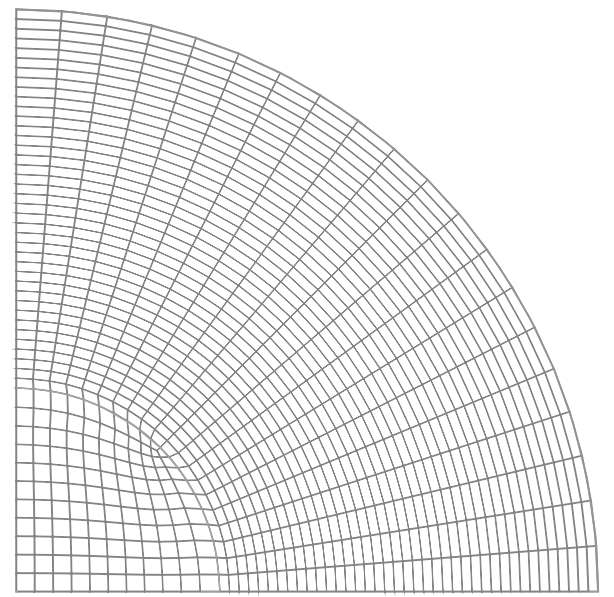

Fig. 18 Undeformed mesh of the blank for the cylindrical cup drawing test.

Fig. 19 shows the predicted outer profile of the blank at the final punch displacement of $40 \mathrm{~mm}$ as function of $\theta$ using the SHB8PS element. This result is compared to the simulation using the Abaqus finite element C3D8R with the same in-plane mesh as SHB8PS and two layers of elements in the thickness direction. The results are also compared to the experiment from Numisheet 2002. Both elements predict the correct four-ear profile exhibited by the experiments, the average rim radius predicted with SHB8PS being very close to the experimental one. The punch force evolutions predicted with the two types of elements (Fig. 20) are also similar, with SHB8PS overpredicting (up to 11\%) the load during the transient stage, while C3D8R underestimating it during the subsequent quasistationary stage. 


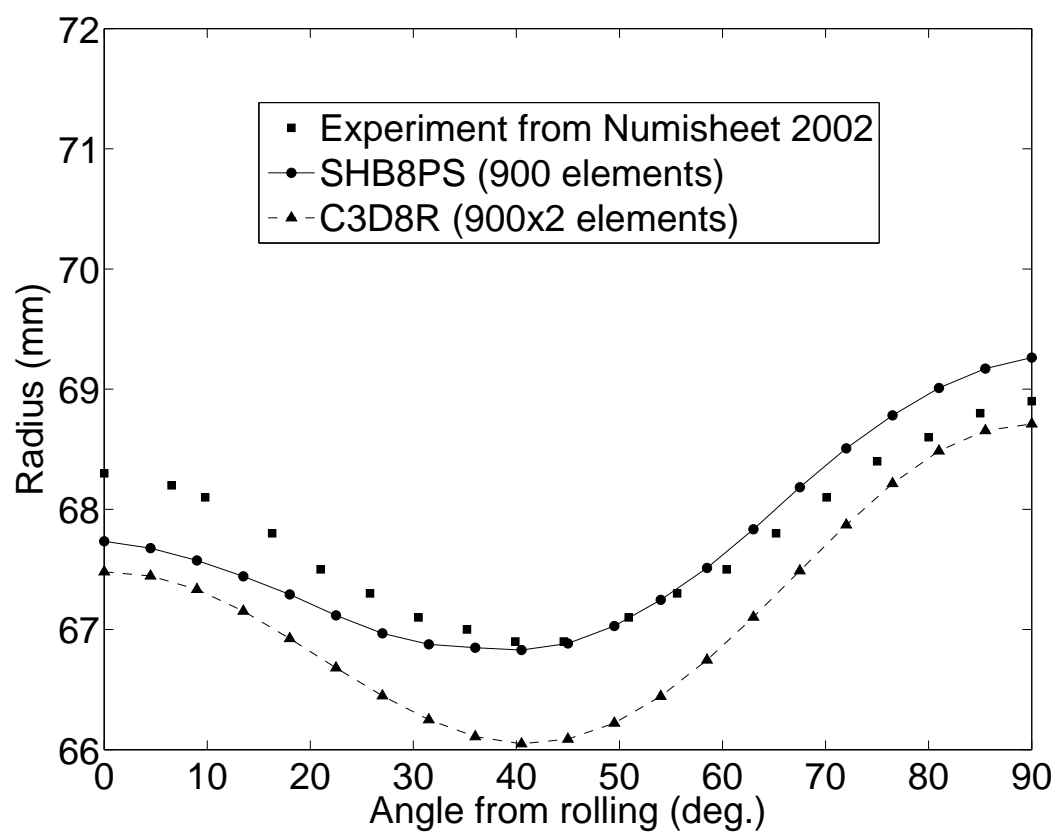

Fig. 19 Outer profile of the blank at the final punch displacement.

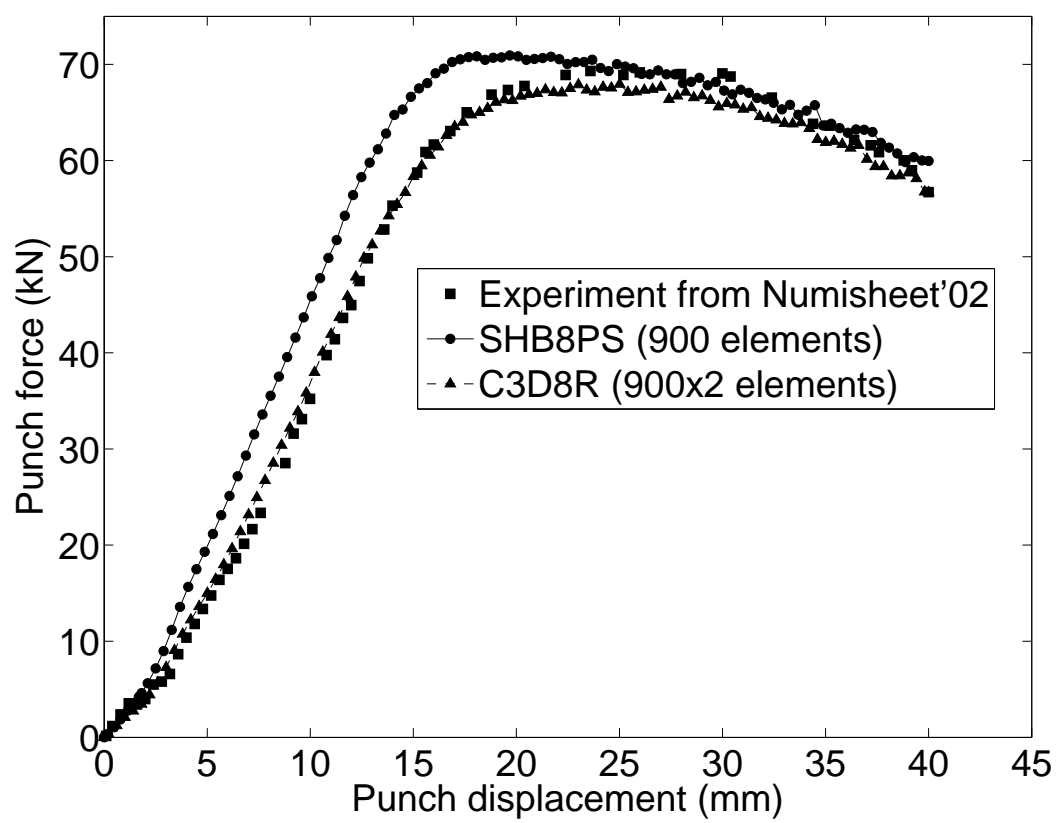

Fig. 20 Punch force vs. punch displacement plots for the cylindrical cup drawing test problem. 


\section{Concluding remarks}

An extended version of the solid-shell finite element SHB8PS has been implemented into the implicit finite element code Abaqus/Standard via the UEL subroutine. A modular finite element implementation was proposed, with clear delimitation between: interpolation, kinematics, constitutive state update, element integration, and stabilization. It is believed that this approach can be successfully and easily extended to other choices for any of these independent modules, which were described in detail. This version of the SHB8PS element can deal with problems involving anisotropic elastic-plastic behavior at large deformations, which are typical in sheet metal forming applications. The formulation of this element employs a combination of the reduced integration scheme with the assumed strain method and a specific projection to eliminate locking phenomena. The resulting hourglass modes are controlled using a physical self-adapting stabilization procedure.

The number of integration points through the thickness direction can be freely selected, avoiding the computational cost of including several element layers. This aspect makes the element very competitive for sheet metal forming applications. Another interesting feature is the convenient fully three-dimensional framework on which this solid-shell element is based (eight-node hexahedron with only translational degrees of freedom per node). Also, the presence of eight physical nodes allows for the realistic modeling of double-sided contact.

The capabilities of SHB8PS element have been shown through several applications involving various types of non-linearities: geometric, material and contact.

Numisheet benchmark problems, characterized by evolving contact, bending-dominated straining mode and large springback, were used to validate the effectiveness of the new element for sheet forming applications.

The unconstrained cylindrical bending of two sheets made of 6111-T4 aluminum alloy and High Strength Steel was considered. Good agreement with experimental results for the punch force has been obtained. At equivalent mesh density, SHB8PS performs at least as well as the most accurate (and expensive) solid elements. However, this accuracy is achieved at a lower cost as several layers of linear solid elements are replaced with one single layer of SHB8PS elements, simply by adjusting the number of integration points. The element performance was also evaluated on springback predictions. Once again, consistently with the load--displacement results, the springback predictions were found in good agreement with the experimental measurements.

Finally, the performance of the element was assessed in the framework of anisotropy by investigating the cylindrical cup drawing test. The earing profile was well predicted.

Acknowledgements The authors are grateful to the Agence Nationale de la Recherche - ANR (France) for its financial support through the Mat\&Pro project FORMEF. The first author is grateful to the Région Lorraine for its financial support.

\section{References}

1. Abed-Meraim F, Combescure A (2002) SHB8PS-a new adaptive, assumed-strain continuum mechanics shell element for impact analysis. Computers and Structures 80:791-803

2. Abed-Meraim F, Combescure A (2009) An improved assumed strain solid-shell element formulation with physical stabilization for geometric non-linear applications and elastic-plastic stability analysis. International Journal for Numerical Methods in Engineering 80(13):1640-1686

3. Alves de Sousa R, Cardoso R, Fontes Valente R, Yoon J, Grácio J, Natal Jorge R (2005) A new onepoint quadrature enhanced assumed strain (EAS) solid-shell element with multiple integration points along thickness: part I - geometrically linear applications. International Journal for Numerical Methods in Engineering 62:952-977

4. Alves de Sousa R, Cardoso R, Fontes Valente R, Yoon J, Grácio J, Natal Jorge R (2006) A new one-point quadrature enhanced assumed strain (EAS) solid-shell element with multiple integration points along thickness: Part II - nonlinear applications. International Journal for Numerical Methods in Engineering $67: 160-188$

5. Alves de Sousa R, Yoon J, Cardoso R, Fontes Valente R, Grácio J (2007) On the use of a reduced enhanced solid-shell (RESS) element for sheet forming simulations. International Journal of Plasticity 23:490-515

6. Alves de Sousa R, Correia J, Simões F, Ferreira J, Cardoso R, Grácio J, Barlat F (2008) Unconstrained springback behavior of $\mathrm{Al}-\mathrm{Mg}$-Si sheets for different sitting times. International Journal of Mechanical Sciences 50(9):1381-1389 
7. Areias P, César de Sá J, Conceição António C, Fernandes A (2003) Analysis of 3D problems using a new enhanced strain hexahedral element. International Journal for Numerical Methods in Engineering 58:1637-1682

8. Belytschko T, Bindeman L (1993) Assumed strain stabilization of the eight node hexahedral element. Computer Methods in Applied Mechanics and Engineering 105:225-260

9. Bui Q, Papeleux L, Ponthot J (2004) Numerical simulation of springback using enhanced assumed strain elements. Journal of Materials Processing Technology 153-154:314-318

10. Cardoso R, Yoon J, Valente R (2007) Enhanced one-point quadrature shell element for nonlinear applications. International Journal for Numerical Methods in Engineering 69:627-663

11. Cardoso R, Yoon J, Mahardika M, Choudhry S, Alves de Sousa R, Fontes Valente R (2008) Enhanced assumed strain (EAS) and assumed natural strain (ANS) methods for one-point quadrature solid-shell elements. International Journal for Numerical Methods in Engineering 75:156-187

12. Cho C, Park H, Lee S (1998) Stability analysis using a geometrically nonlinear assumed strain solid-shell element model. Finite Elements in Analysis and Design 29:121-135

13. Domissy E (1997) Formulation et évaluation d'éléments finis volumiques modifiés pour l'analyse linéaire et nonlinéaire des coques. $\mathrm{PhD}$ thesis, Université de Technologie de Compiègne, France

14. Eberlein R, Wriggers P (1999) Finite element concepts for finite elastoplastic strains and isotropic stress response in shells: theoretical and computational analysis. Computer Methods in Applied Mechanics and Engineering 171:243-279

15. Eriksson A, Pacoste C, Zdunek A (1999) Numerical analysis of complex instability behaviour using incremental-iterative strategies. Computer Methods in Applied Mechanics and Engineering 179:265-305

16. Fish J, Belytschko T (1988) Elements with embedded localization zones for large deformation problems. Computers and Structures 30:247-256

17. Fontes Valente R, Alves de Sousa R, Natal Jorge R (2004) An enhanced strain 3D element for large deformation elastoplastic thin-shell applications. Computational Mechanics 48:38-52

18. Haddag B, Balan T, Abed-Meraim F (2007) Investigation of advanced strain-path dependent material models for sheet metal forming simulations. International Journal of Plasticity 23:951-979

19. Haddag B, Abed-Meraim F, Balan T (2009) Strain localization analysis using a large deformation anisotropic elastic-plastic model coupled with damage. International Journal of Plasticity 25:1970-1996

20. Hauptmann R, Schweizerhof K (1998) A systematic development of solid-shell element formulations for linear and non-linear analyses employing only displacement degrees of freedom. International Journal for Numerical Methods in Engineering 42:49-69

21. Hill R (1950) The mathematical theory of plasticity. Oxford Univesity Press, Oxford

22. Hughes T (1980) Generalization of selective integration procedures to anisotropic and nonlinear media. International Journal for Numerical Methods in Engineering 15:1413-1418

23. Hughes T, Winget J (1980) Finite rotation effects in numerical integration of rate constitutive equation arising in large deformation analysis. International Journal for Numerical Methods in Engineering 15:18621867

24. Hughes T, Cohen M, Haroun M (1978) Reduced and selective integration techniques in finite element analysis of plates. Nuclear Engineering Design 46:203-222

25. Kim K, Liu G, Han S (2005) A resultant 8-node solid-shell element for geometrically nonlinear analysis. Computational Mechanics 35:315-331

26. Klinkel S, Gruttmann F, Wagner W (2006) A robust non-linear solid-shell element based on a mixed variational formulation. Computer Methods in Applied Mechanics and Engineering 195:179-201

27. Leahu-Aluas I, Abed-Meraim F (2011) A proposed set of popular limit-point buckling benchmark problems. Structural Engineering and Mechanics 38:767-802

28. Legay A, Combescure A (2003) Elastoplastic stability analysis of shells using the physically stabilized finite element SHB8PS. International Journal for Numerical Methods in Engineering 57:1299-1322

29. Meinders T, Konter A, Meijers S, Atzema E, Kappert H (2005) A sensitivity analysis on the springback behavior of the unconstrained bending problem. In: NUMISHEET 2005, 6th international conference and workshop on numerical simulation of 3D sheet metal forming processes, Detroit, Michigan, USA

30. Meinders T, Konter A, Meijers S, Atzema E, Kappert H (2006) A sensitivity analysis on the springback behavior of the unconstrained bending problem. International Journal of Forming Processes 9(3):365-402

31. Miehe C (1998) A theoretical and computational model for isotropic elastoplastic stress analysis in shells at large strains. Computer Methods in Applied Mechanics and Engineering 155:193-233

32. Numisheet 2002 Organization Commitee (2002) In: Proceedings of the fifth international conference and workshop on numerical simulation of 3D sheet forming processes, Jeju Island, Korea

33. Rabahallah M, Balan T, Bouvier S, Teodosiu C (2009) Time integration scheme for the finite element implementation of elasto-plastic models based on anisotropic strain-rate potentials. International Journal for Numerical Methods in Engineering 80:381-402

34. Reese S (2002) On the equivalence of mixed element formulations and the concept of reduced integration in large deformation problems. International Journal of Nonlinear Sciences and Numerical Simulation 3:1-33

35. Reese S (2005) On a physically stabilized one point finite element formulation for three-dimensional finite elastoplasticity. Computer Methods in Applied Mechanics and Engineering 194:4685-4715

36. Reese S (2007) A large deformation solid-shell concept based on reduced integration with hourglass stabilization. International Journal for Numerical Methods in Engineering 69:1671-1716

37. Reese S, Wriggers P (2000) A stabilization technique to avoid hourglassing in finite elasticity. International Journal for Numerical Methods in Engineering 48:79-109 
38. Reese S, Kussner M, Reddy B (1998) A new stabilization technique for finite element in non-linear elasticity. International Journal for Numerical Methods in Engineering 44:1617-1652

39. Schwarze M, Reese S (2009) A reduced integration solid-shell finite element based on the EAS and the ANS concept - geometrically linear problems. International Journal for Numerical Methods in Engineering 80:1322-1355

40. Schwarze M, Reese S (2011) A reduced integration solid-shell finite element based on the EAS and the ANS concept - large deformation problems. International Journal for Numerical Methods in Engineering 85:289-329

41. Schwarze M, Vladimirov IN, Reese S (2011) Sheet metal forming and springback simulation by means of a new reduced integration solid-shell finite element technology. Computer Methods in Applied Mechanics and Engineering 200:454-476

42. Simo J, Hughes T (1986) On the variational foundations of assumed strain methods. Journal of Applied Mechanics (ASME) 53:51-54

43. Simo J, Kennedy J (1992) On a stress resultant geometrically exact shell model: Part V - Nonlinear plasticity: formulation and integration algorithms. Computer Methods in Applied Mechanics and Engineering 96:133-171

44. Simo J, Rifai M (1990) A class of mixed assumed strain methods and the method of incompatible modes. International Journal for Numerical Methods in Engineering 29:1595-1638

45. Sze K, Yao L (2000) A hybrid stress ANS solid-shell element and its generalization for smart structure modelling. part I: solid-shell element formulation. International Journal for Numerical Methods in Engineering 48:545-564

46. Sze K, Zheng S (1999) A hybrid stress nine-node degenerated shell element for geometric nonlinear analysis. Computational Mechanics 23:448-456

47. Sze K, Zheng S (2002) A stabilized hybrid-stress solid element for geometrically nonlinear homogeneous and laminated shell analyses. Computer Methods in Applied Mechanics and Engineering 191:1945-1966

48. Sze K, Liu X, Lo S (2004) Popular benchmark problems for geometric nonlinear analysis of shells. Finite Elements in Analysis and Design 40:1551-1569

49. Vu-Quoc L, Tan X (2003) Optimal solid-shells for non-linear analyses of multilayer composites. I. Statics. Computer Methods in Applied Mechanics and Engineering 192:975-1016

50. Wriggers P, Eberlein R, Reese S (1996) A comparison of three-dimensional continuum and shell elements for finite plasticity. International Journal of Solids and Structures 33:3309-3326

51. Yoon J, Pourboghrat F, Chung K, Yang D (2002) Springback prediction for sheet metal forming process using a 3D hybrid membrane/shell method. International Journal of Mechanical Sciences 44:2133-2153

52. Zienkiewicz O, Taylor R, Too J (1971) Reduced integration technique in general analysis of plates and shells. International Journal for Numerical Methods in Engineering 3:275-290 